Report No. BMI-1186

UC-4 Chemistry - General

(TID-4500, 13th Ed.)

Contract No. W-7405-eng-92

$$
B M 1-11+6
$$

\title{
VAPOR PRESSURE AND EQUILIBRIUM STUDIES OF THE SODIUM FLUORIDE-BERYLLIUM FLUORIDE SYSTEM
}

\author{
by
}

Karl A. Sense

Richard W. Stone

R. B. Filbert, Jr.

May 27, 1957

\author{
BATTELLE MEMORIAL INSTITUTE \\ $505 \mathrm{King}$ Avenue \\ Columbus 1, Ohio
}




\section{DISCLAIMER}

This report was prepared as an account of work sponsored by an agency of the United States Government. Neither the United States Government nor any agency Thereof, nor any of their employees, makes any warranty, express or implied, or assumes any legal liability or responsibility for the accuracy, completeness, or usefulness of any information, apparatus, product, or process disclosed, or represents that its use would not infringe privately owned rights. Reference herein to any specific commercial product, process, or service by trade name, trademark, manufacturer, or otherwise does not necessarily constitute or imply its endorsement, recommendation, or favoring by the United States Government or any agency thereof. The views and opinions of authors expressed herein do not necessarily state or reflect those of the United States Government or any agency thereof. 


\section{DISCLAIMER}

Portions of this document may be illegible in electronic image products. Images are produced from the best available original document. 


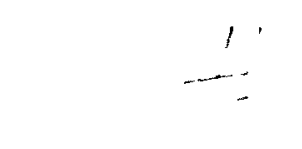

TABLE OF CONTENTS

$\underline{\text { Page }}$

ABSTRACT ............................. . . . . 1

INTRODUCTION . . . . . . . . . . . . . . . . . . . . . 1

EXPERIMENTAL PROCEDURE . . . . . . . . . . . . . . . . . 1

Description of Method and Apparatus ............... . 1

Materials ............................ 1

RESULTS . . . . . . . . . . . . . . . . . . . . . 2

The Vapor Pressure of $\mathrm{BeF}_{2}$. . . . . . . . . . . . . . 2

The Vapor Pressure of $\mathrm{NaF}$. . . . . . . . . . . . . . . 5

The Vapor Pressures of the $\mathrm{NaF}_{-\mathrm{BeF}_{2}}$ System . . . . . . . . . 8

Total Vapor Pressures of the $\mathrm{NaF}-\mathrm{BeF}_{2}$ System . . . . . . . . . . . 24

REFERENCES . . . . . . . . . . . . . . . . . . 30 


\title{
1 \\ $5, \cdots+20$ \\ VAPOR PRESSURES AND EQUILIBRIUM STUDIES OF THE
SODIUM FLUORIDE-BERYLLIUM FLUORIDE SYSTEM
}

Karl A. Sense, Richard W. Stone, and Robert B. Filbert, Jr.

\begin{abstract}
$A$ new study made on the vapor pressure of $B e F_{2}$ over the temperature interval 802 to $1025 \mathrm{C}$ showed good agreement with previous data taken over the 802-968 C range. Excessive scatter of the vapor-pressure data in the lower temperature region prevented a melting-point determination of $\mathrm{BeF}_{2}$ by the transpiration method alone. Thermal analysis showed the melting point to be about $545 \mathrm{C}$. Vapor pressures of the $\mathrm{NaF}-\mathrm{BeF} 2$ system were measured over the range 509 to $1061 \mathrm{C}$. On the basis of previously developed theory it was concluded that the complex $\mathrm{NaBeF}_{3}$ exists in the vapor phase in addition to $\mathrm{NaF}$ and $\mathrm{BeF}_{2}$. Resolution of the vapor phase on this basis led to the disclosure that another complex must exist in the vapor phase. This additional complex was postulated as being $\mathrm{Na}_{2} \mathrm{BeF}_{4}$. In the absence of enough equations to solve for all the unknowns, a system of partial pressures was approximated within the framework of the experimental data. This system was made self-consistent with respect to smoothed plots of the equilibrium constants as functions of temperature. A liquid-vapor phase diagram and plots showing how the total pressure varies with the composition are presented.
\end{abstract}

\section{INTRODUCTION}

This work is a continuation of the study of the physical properties of fused-salt systems which was started with the investigation of the $\mathrm{NaF}-\mathrm{ZrF}_{4}$ system previously reported. (1) In the $\mathrm{NaF}-\mathrm{ZrF}_{4}$ report, a theory was presented for the determination of vapor-phase molecular complexes. The report on the $\mathrm{NaF}-\mathrm{BeF}_{2}$ system augments the study of molecular complexes in the vapor phase.

\section{EXPERIMENTAL PROCEDURE}

\section{Description of Method and Apparatus}

The method and apparatus used have been adequately described previously. $(1,2)$ The only change from previous procedure consisted in improved oxygen removal from the argon which was used as a carrier gas. This was accomplished by passing the argon over heated uranium chips after most of the oxygen had been removed by heated copper turnings.

\section{Materials}

The fused salt mixtures were supplied by the Mound Laboratory at Miamisburg, Ohio, and the Oak Ridge National Laboratory at Oak Ridge, Tennessee. Table 1 is a (1) References are listed at the end of this report. 
list of mixtures used and the name of the laboratory that prepared the samples. Composition of the salt was based on numerous analyses made at Battelle.

TABLE 1. COMPOSITION OF STARTING MATERIALS

\begin{tabular}{|c|c|c|c|}
\hline \multicolumn{2}{|c|}{ Composition } & \multirow{2}{*}{$\begin{array}{c}\text { Batch } \\
\text { (Oak Ridge Designation) }\end{array}$} & \multirow[b]{2}{*}{ Laboratory } \\
\hline Mole Per Cent NaF & Mole Per Cent $\mathrm{BeF}_{2}$ & & \\
\hline 85.1 & 14.9 & -- & Mound \\
\hline 80.9 & 19.1 & EE-741 & Oak Ridge \\
\hline 75.6 & 24.4 & -- & Mound \\
\hline 68.5 & 31.5 & $E E-740$ & Oak Ridge \\
\hline 60.5 & 39.5 & $\ldots$ & Mound \\
\hline 49.9 & 50.1 & -- & Mound \\
\hline 41.1 & 58.9 & -- & Mound \\
\hline 25.9 & 74.1 & -- & Mound \\
\hline
\end{tabular}

In most cases, the composition of the salt mixtures changed slightly during the runs because of the preferential vaporization of the more volatile component. Corrections were made for this effect, and the average compositions are listed on the various plots with the proper curves.

\section{RESULTS}

\section{The Vapor Pressure of BeF2}

The vapor pressure of $\mathrm{BeF}_{2}$ had been measured some time ago. (2) Because the apparatus and techniques in measuring vapor pressures have been improved since publication of the original report, another set of measurements was made. The results of these measurements are treated in two parts: those obtained for temperatures greater than about $800 \mathrm{C}$ and those obtained below that temperature. For temperatures greater than about $800 \mathrm{C}$, relatively little difficulty was experienced in obtaining reasonably consistent data (see Table 2). The results compare favorably with those given in the previous report. (2) Figure $l$ is a plot of the recent measurements and with the best curve* obtained, as well as the best curve obtained for the previous set of data. The new vapor-pressure curve has a somewhat flatter slope, resulting in a heat of vaporization value of

$$
\Delta \mathrm{H}_{\mathrm{v}}=50.1 \mathrm{kcal} \text { per } \mathrm{g}-\mathrm{mole} \text {, }
$$

as compared with the old value of $50.9 \mathrm{kcal}$ per $\mathrm{g}-\mathrm{mole}$. At $\frac{\mathrm{l}}{\mathrm{T}(\mathrm{K})}=7.8 \times 10^{-4}$, the new vapor-pressure curve yields a value about 10 per cent lower than the previous one,

In the least-square treatment, the data were weighted, since in some instances two or more analyses were made for a single run, 
TABLE 2. VAPOR PRESSURES OF BeF 2

\begin{tabular}{|c|c|c|c|c|}
\hline Temperature, & $\frac{\text { Pressur }}{\text { Observed }}$ & $\frac{\text { mercury }}{\text { Calculated }}$ & $\begin{array}{c}\text { Deviation, } \\
\text { per cent }\end{array}$ & $\begin{array}{l}\text { Flow Rate of } \\
\text { Carrier Gas, } \\
\mathrm{cm}^{3} \text { per min }\end{array}$ \\
\hline 1025 & $106.2 a$ & 108.6 & -2.2 & 8.5 \\
\hline 1010 & 88.9 & 86.3 & +3.0 & 11.5 \\
\hline 989.6 & $70.4 a$ & 63.1 & +11.6 & 9.0 \\
\hline 974.8 & $50.7 \mathrm{~b}$ & 49.8 & +1.8 & 11.2 \\
\hline 960.5 & $40.4 b$ & 39.4 & +2.4 & 10.0 \\
\hline 945.9 & $31.6 a$ & 30.9 & +2.4 & 14.9 \\
\hline 932.0 & $24.4 a$ & 24.3 & +1.1 & 18.9 \\
\hline 932.0 & $22.1 \mathrm{~b}$ & 24.3 & -9.0 & 21.2 \\
\hline 917.4 & $18.2 \mathrm{~b}$ & 18.8 & -3.1 & 19.9 \\
\hline 917.4 & $18.4 a$ & 18.8 & -2.1 & 20.9 \\
\hline 900.7 & $13.86 a$ & 13.93 & -0.5 & 23.3 \\
\hline 889.7 & $11.25 a$ & 11.37 & -1.1 & 23.6 \\
\hline 889.1 & 10.85 & 11.17 & -2.8 & 23.0 \\
\hline 877.6 & $8.59 b$ & 9.06 & -5.2 & 20.2 \\
\hline 863.0 & $6.94 a$ & 6.83 & +1.6 & 20.9 \\
\hline 850.3 & 5.48 & 5.32 & +3.1 & 31.1 \\
\hline 839.5 & $4.05 a$ & 4.28 & -5.3 & 31.2 \\
\hline 838.0 & $4.27 \mathrm{~b}$ & 4.15 & +2.9 & 30.8 \\
\hline 825.4 & 3.47 & 3.20 & +8.5 & 32.4 \\
\hline 813.9 & 2.70 & 2.51 & +7.4 & 40.1 \\
\hline 802.2 & 2.05 & 1.95 & +5.2 & 41.1 \\
\hline
\end{tabular}

Note: $a=$ Pressure based upon average of two analyses.

$b=$ Pressure based upon average of three analyses. 
4

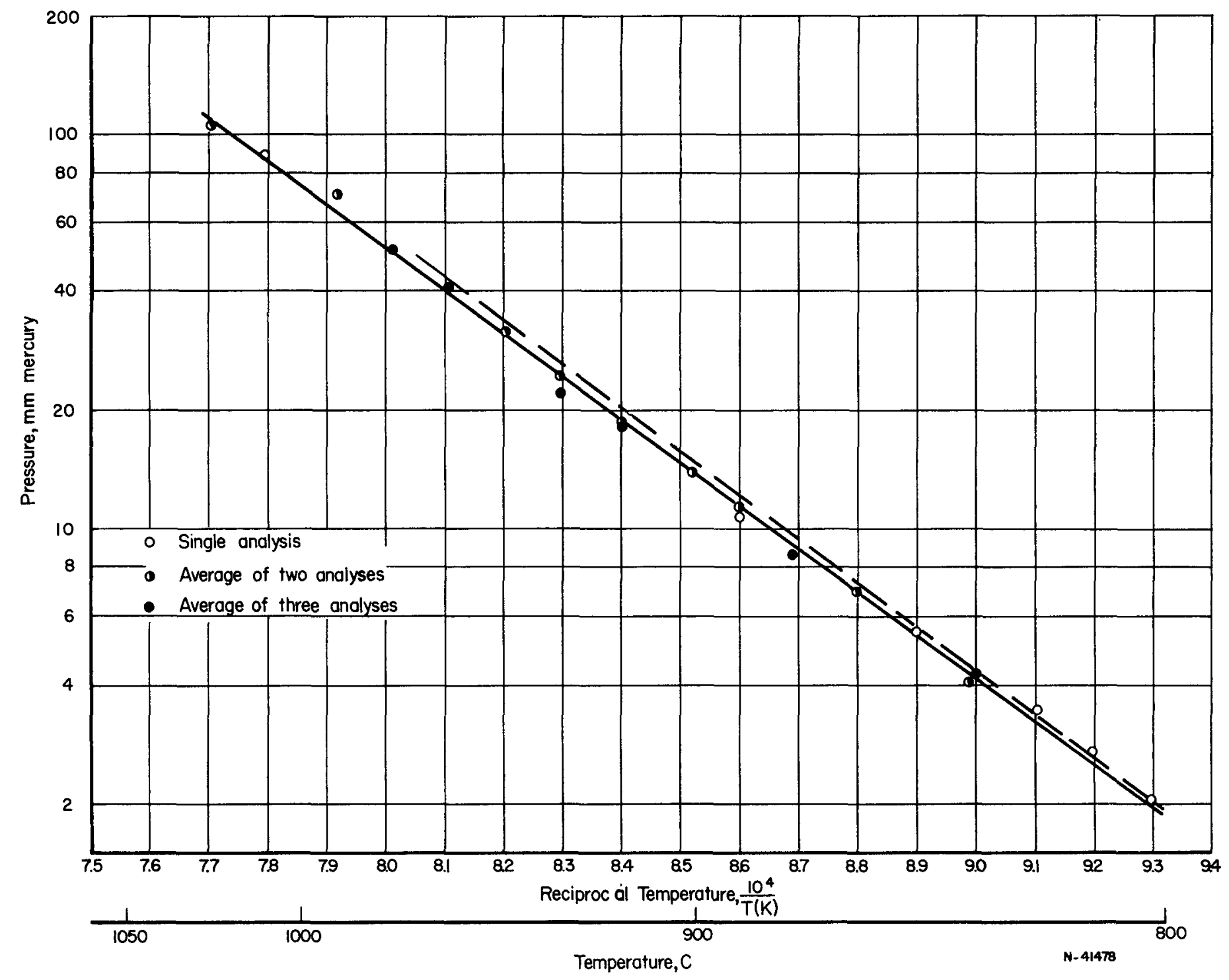

A

FIGURE 1. VAPOR PRESSURES OF PURE BeF 2 OVER THE RANGE $802 \mathrm{C}$ TO $1025 \mathrm{C}$ Solid curve is result of weighted least-square treatment of data. Dashed curve is result of previous study. 
while at $\frac{1}{\mathrm{~T}(\mathrm{~K})}=9.3 \times 10^{-4}$, it is only about 4 per cent lower. The revised vapor-pressure equation which holds for the temperature interval 802 to $1025 \mathrm{C}$ is

$$
\log \mathrm{p}=10.466-\frac{10943}{\mathrm{~T}(\mathrm{~K})}
$$

where $p$ is measured in mm of mercury.

$$
\text { The extrapolated boiling point }=1170 \mathrm{C} \text {. }
$$

Below about $800 \mathrm{C}$, difficulties were encountered in obtaining consistent data. In addition to the data given, 13 additional runs were made between $\frac{1}{\mathrm{~T}(\mathrm{~K})}=9.6 \times 10^{-4}$ $(770 \mathrm{C})$ and $\frac{1}{\mathrm{~T}(\mathrm{~K})}=9.9 \times 10^{-4}(738 \mathrm{C})$. All of these runs were made with a carrier-gas

flow rate of very nearly $50 \mathrm{~cm}^{3}$ per min. The oxygen was removed from the carrier gas by heated copper only. The results are given in Figure 2. No firm vapor-pressure values were obtained for these runs because analyses of the condensates showed the amount of beryllium present to be below the detection limit. The following explanation was postulated. Enough oxygen was left in the carrier gas to react with $B e F_{2}$ and form a thin film of $\mathrm{BeO}$ covering the $\mathrm{BeF}_{2}$ charge. Below about $800 \mathrm{C}$, the viscosity of $\mathrm{BeF}_{2}$ increased sufficiently that the coating of $\mathrm{BeO}$ remained on the surface, making it difficult for the $\mathrm{BeF}_{2}$ molecules to vaporize. In an attempt to solve the problem, the carrier gas was passed over copper and then over heated uranium chips for further oxygen removal, and the runs were made at much lower flow rates to enhance the possibility of equilibrium conditions existing between vapor and liquid. Figure 2 shows graphically the results obtained.

Even though considerable scatter is evident for the firm data, no break in the $\mathrm{pBeF}_{2}$ curve is evident above about $700 \mathrm{C}$. This shows the melting point of $\mathrm{BeF}_{2}$ to be considerably lower than indicated from previous vapor-pressure work. (2) Below about $700 \mathrm{C}$ the scatter of the data permits no interpretation. It seems from these investigations that it would be difficult to obtain the melting point of $\mathrm{BeF}_{2}$ from vapor-pressure measurements alone.

Since the scatter of the data on pure $\mathrm{BeF}_{2}$ was excessive below about $700 \mathrm{C}$, it was considered of interest to obtain vapor-pressure data for the 26 mole per cent NaF74 mole per cent $\mathrm{BeF}_{2}$ composition below $700 \mathrm{C}$. It was hoped that the presence of $\mathrm{NaF}$ would reduce the viscosity of $\mathrm{BeF}_{2}$ sufficiently to result in consistent vapor-pressure data. Figure 3 shows the results obtained over the 509 to $977 \mathrm{C}$ range. Though the data scatter somewhat below $635 \mathrm{C}$, excessive scatter starts only below $535 \mathrm{C}$. A break in the curve is not evident above that temperature.

\section{The Vapor Pressure of $\mathrm{NaF}$}

The vapor pressures of $\mathrm{NaF}$ have been reported previously. (1) Since no additional data are available, the derived P-T relations remain unchanged. From 934 to $996 \mathrm{C}$, the melting point,

$$
\log p=11.3315-\frac{14855.7}{T(K)}
$$




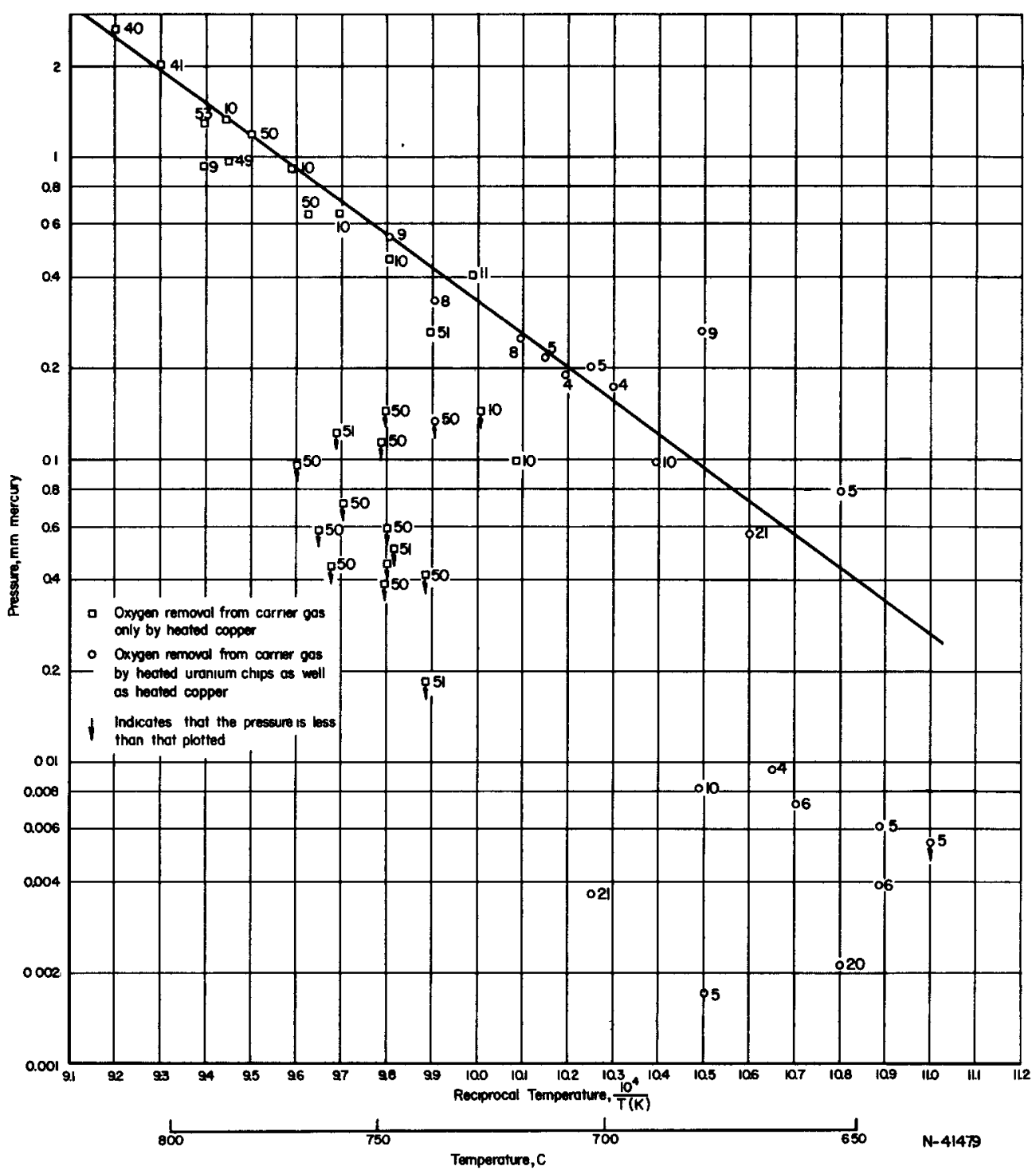

FIGURE 2. VAPOR PRESSURES OF PURE BeF 2 OVER THE RANGE $636 \mathrm{C}$ TO $814 \mathrm{C}$

Figures represent flow rates in $\mathrm{cm}^{3} / \mathrm{min}$ of carrier gas for each run. Curve obtained from $\mathrm{P}-\mathrm{T}$ equation derived from data for $802 \mathrm{C}$ to $1025 \mathrm{C}$ range. 


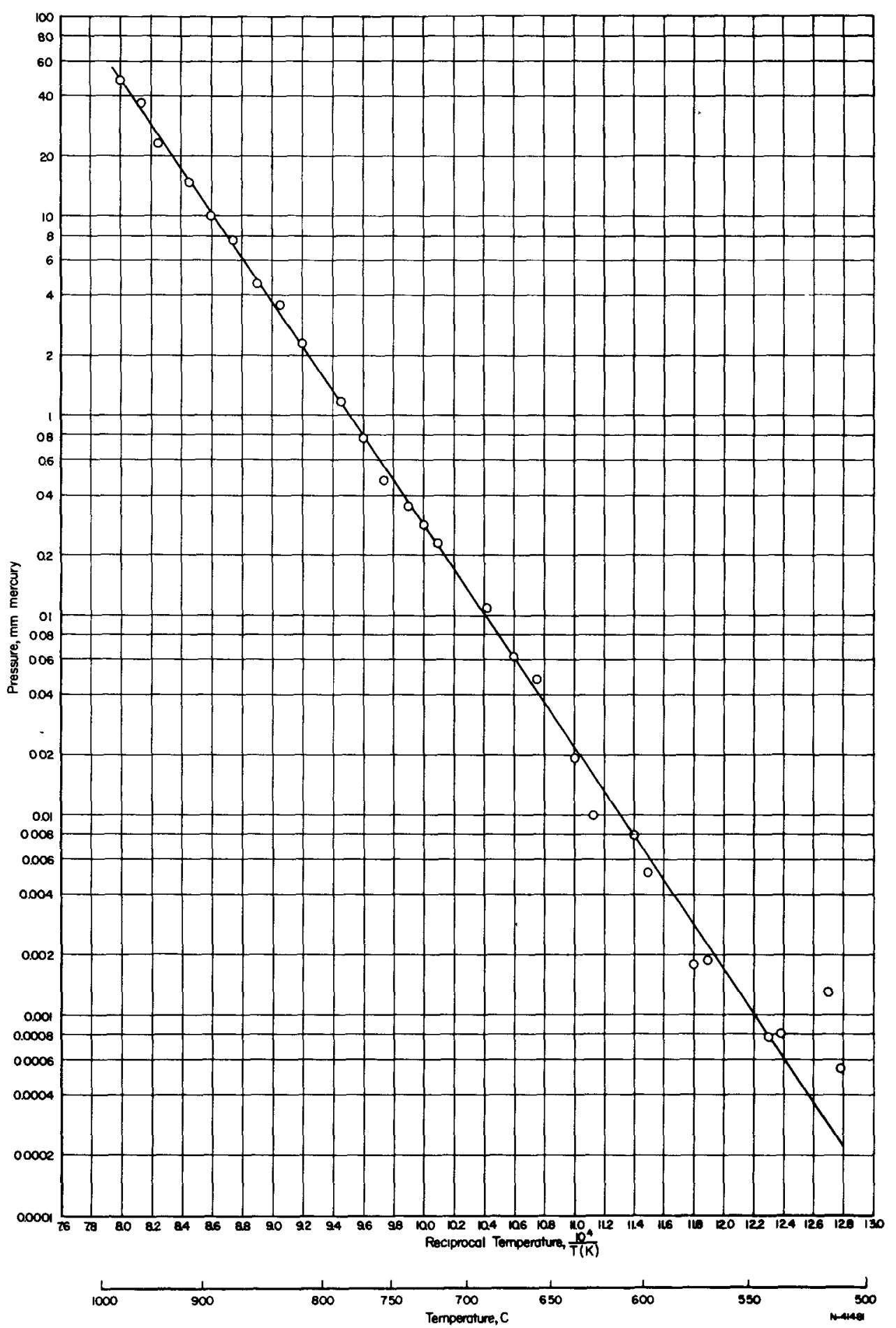

FIGURE 3. PARTIAL PRESSURES OF BEF 2 FOR 26.1 MOLE PER CENT NaF73. 9 MOLE PER CENT BeF 2 COMPOSITION OVER THE RANGE 509 C TO 977 C 
From 996 to $1075 \mathrm{C}$,

$$
\log \mathrm{p}=9.4188-\frac{12428.3}{\mathrm{~T}(\mathrm{~K})},
$$

where $\mathrm{p}$ is measured in $\mathrm{mm}$ mercury.

The Vapor Pressures of the NaF-BeF 2 System

Molecular Species in the Vapor Phase

Results of vapor-pressure runs for the $\mathrm{NaF}-\mathrm{BeF}_{2}$ system are given graphically in Figures 4, 5, 6, and 7 and in tabular form in Table 3. The data are presented on the basis that only $\mathrm{NaF}$ and $\mathrm{BeF}_{2}$ exist in the vapor phase. The solid lines represent the best curves through these data. The dashed lines (which coincide to some extent with the solid lines) will be discussed later.

Figure 8 is a partial pressure plot of $\mathrm{NaF}$ and $\mathrm{BeF}_{2}$ as a function of composition at $890 \mathrm{C}$, assuming that only $\mathrm{NaF}$ and $\mathrm{BeF}_{2}$ exist in the vapor phase. Previously presented theory (1) based on the Duhem-Margules equation,

$$
\mathrm{x}_{1}\left(\frac{\partial \ell \mathrm{np}_{1}}{\partial \mathrm{x}_{1}}\right)_{\mathrm{T}, \mathrm{P}}=\mathrm{x}_{2}\left(\frac{\partial \ell \mathrm{np}_{2}}{\partial \mathrm{x}_{2}}\right)_{\mathrm{T}, \mathrm{P}},
$$

discloses that the peak of a partial-pressure curve indicates the presence of a molecular complex in the vapor phase, the composition of the complex being given by the location of the peak. In Figure 8, the peak of the $\mathrm{p}^{\prime \prime} \mathrm{NaF} *$ curve is located at 50 mole per cent $\mathrm{BeF}_{2}$. Hence, the complex is immediately determined as being $\mathrm{NaBeF}$. In accordance with the procedure worked out previously $(1)$, the partial pressures of NaF, $\mathrm{BeF}_{2}$, and $\mathrm{NaBeF}_{3}$ were determined for $890 \mathrm{C}$ and plotted in Figure 9. From this plot the composition which melts at $890 \mathrm{C}$ was determined as being 16.5 mole per cent $\mathrm{BeF}_{2}$. This is in slight disagreement with the phase diagram by Thilo and $\operatorname{Schröder}(3)$, which indicates that this is the melting point for a 15 mole per cent $\mathrm{BeF}_{2}$ composition. Since the solid phase is NaF, p' NaF remains constant over that composition region. The dashed line above it represents the vapor pressure of the supercooled solution. However, the most interesting part of the plot is the appearance of another p' NaF peak in the $\mathrm{NaF}-\mathrm{NaBeF}_{3}$ system. In accordance with theory, this peak is evidence of the existence of an additional molecular complex in the vapor phase. It is clear that the peak of the p' $\mathrm{NaF}$ curve would have to occur between 31.5 and 50 mole per cent $\mathrm{BeF}_{2}$. Starting with the simplest one, the complexes which could have their partial pressure peaks in that region are $\mathrm{Na}_{2} \mathrm{BeF}_{4}, \mathrm{Na}_{3} \mathrm{Be}_{2} \mathrm{~F}_{7}, \mathrm{Na}_{4} \mathrm{Be}_{3} \mathrm{~F}_{10}, \ldots$. Since it seems unlikely that very large molecules exert an appreciable vapor pressure, the assumption is made that the complex $\mathrm{Na}_{2} \mathrm{BeF}_{4}$ exists in the vapor phase together with $\mathrm{NaBeF}_{3}$, $\mathrm{NaF}$, and $\mathrm{BeF}_{2}$.

\footnotetext{
"To avoid confusion, partial pressures calculated on the basis that only $\mathrm{NaF}_{\text {and }} \mathrm{BeF}_{2}$ exist in the vapor phase will be denoted by a double prime("); for a system based on the existence of $\mathrm{NaF}_{1} \mathrm{BeF}_{2}$, and $\mathrm{NaBeF}_{3}$ in the vapor phase, the partial pressures will be denoted by a single prime ('); for a vapor phase assumed to consist of $\mathrm{NaF}, \mathrm{BeF}_{2}, \mathrm{NaBeF}_{3}$, and $\mathrm{Na}_{2} \mathrm{BeF}_{4}$, the partial pressures will be given without any primes.
} 


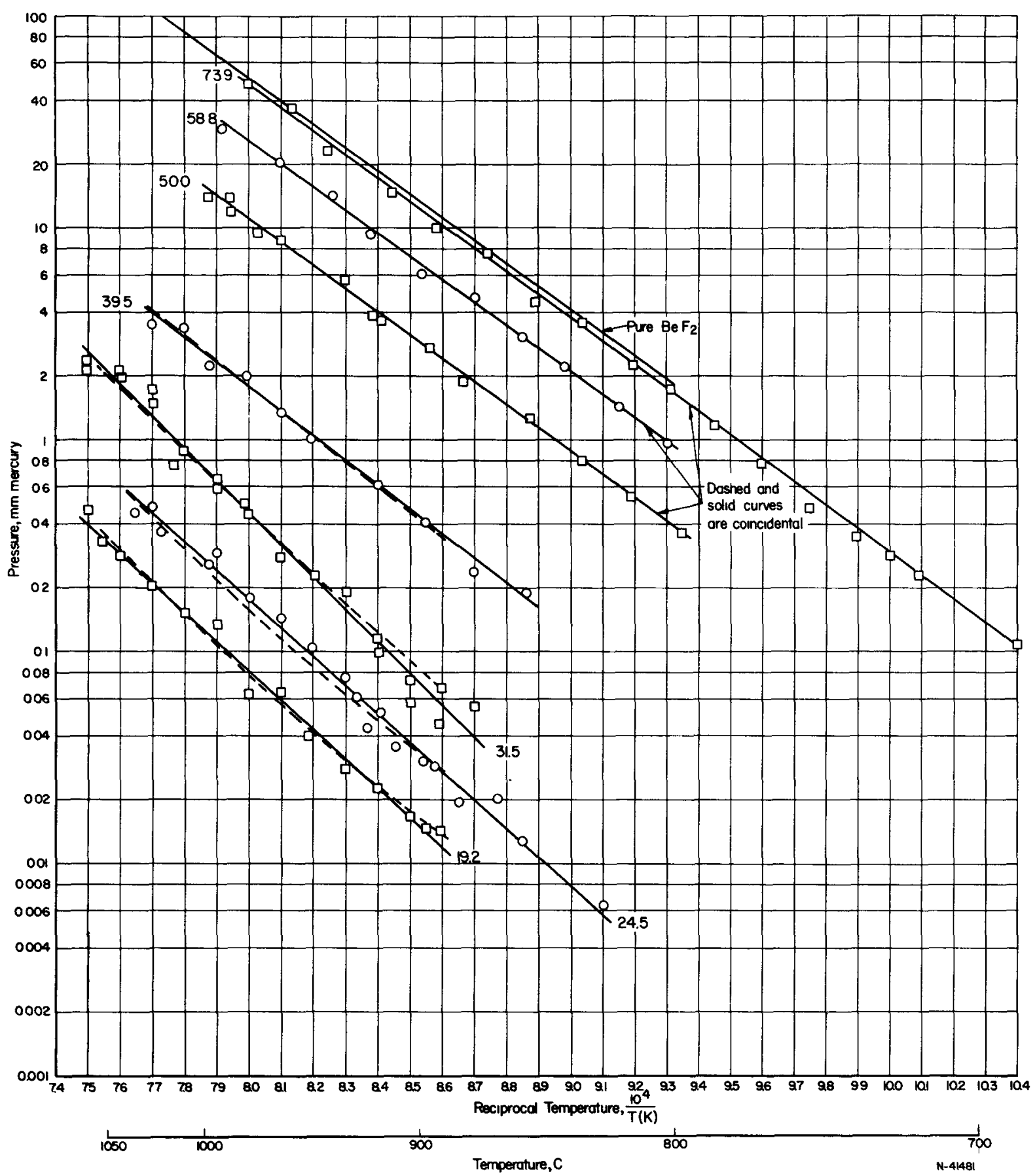

FIGURE 4. PARTIAL PRESSURE OF BeF 2 ON THE BASIS THAT ONLY NaF AND BeF 2 EXIST IN VAPOR PHASE

Solid lines represent best curves through thses data. Dashed lines are explained in text. Figures denote mole per cent $\mathrm{BeF}_{2}$. 


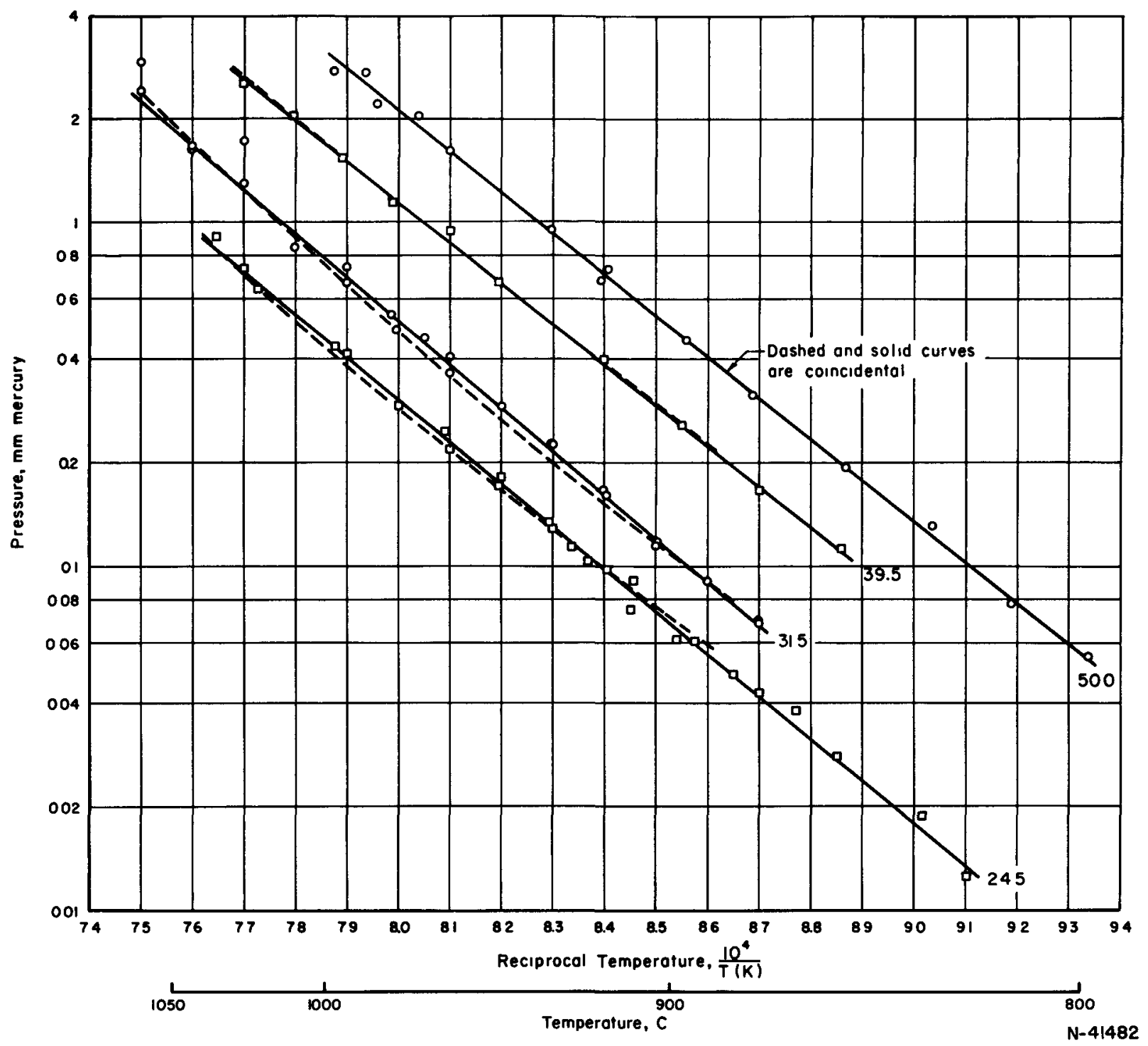

FIGURE 5. PARTIAL PRESSURES OF NaF FOR THE 24.5 TO 50.0 MOLE PER CENT BeF $Z$ REGION Values based on assumption that only $\mathrm{NaF}$ and $\mathrm{BeF}_{2}$ exist in vapor phase. Solid lines represent best curves through these data. Dashed lines are explained in text. 


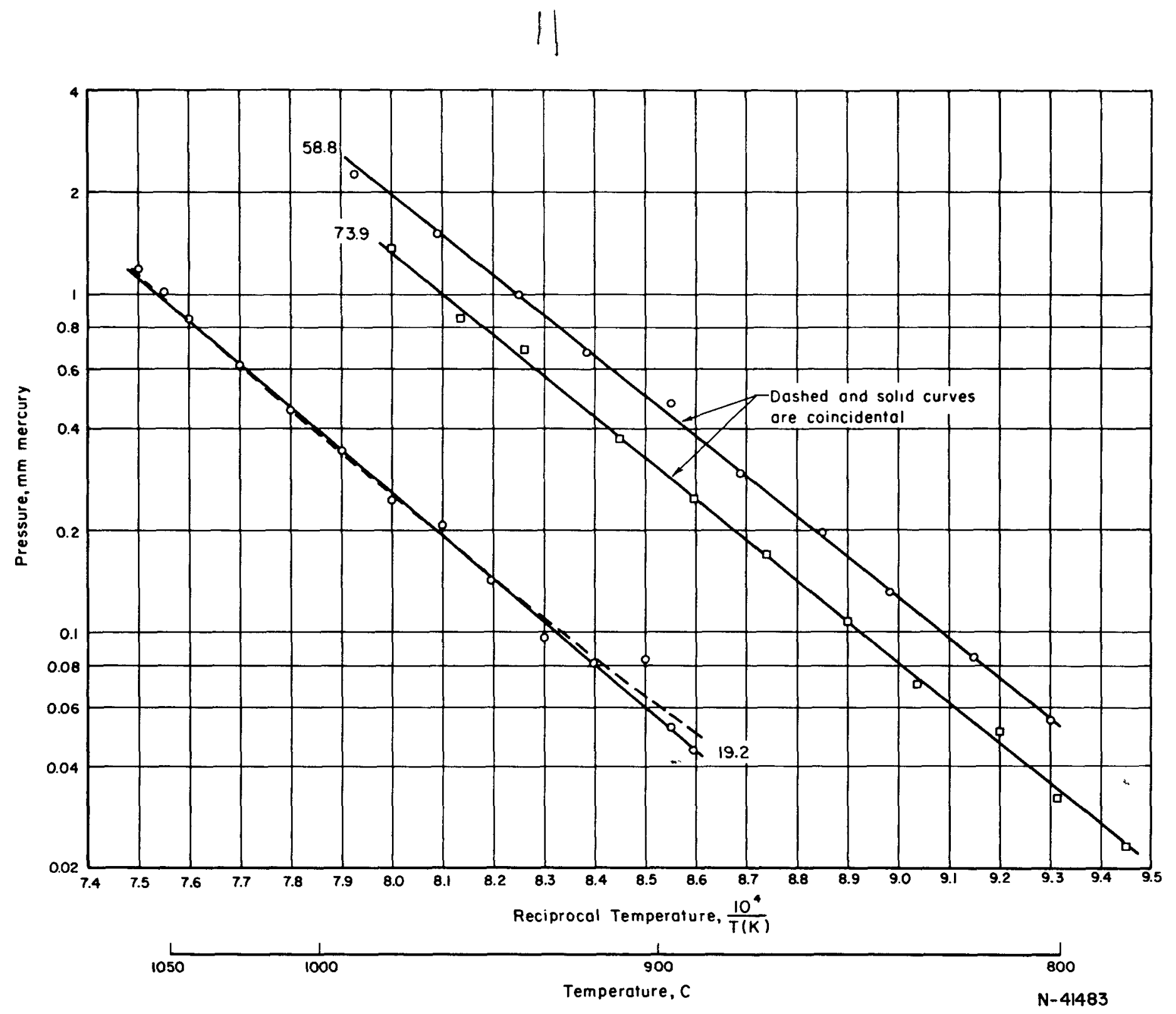

FIGURE 6. PARTIAL PRESSURES OF NaF FOR THE 19.2, 58.8, AND 73.9 MOLE PER CENT BeF 2 REGION

Values based on assumption that only $\mathrm{NaF}$ and $\mathrm{Be} \mathrm{F}_{2}$ exist in vapor phase. Solid lines are best curves through these data. Dashed lines are explained in text. 

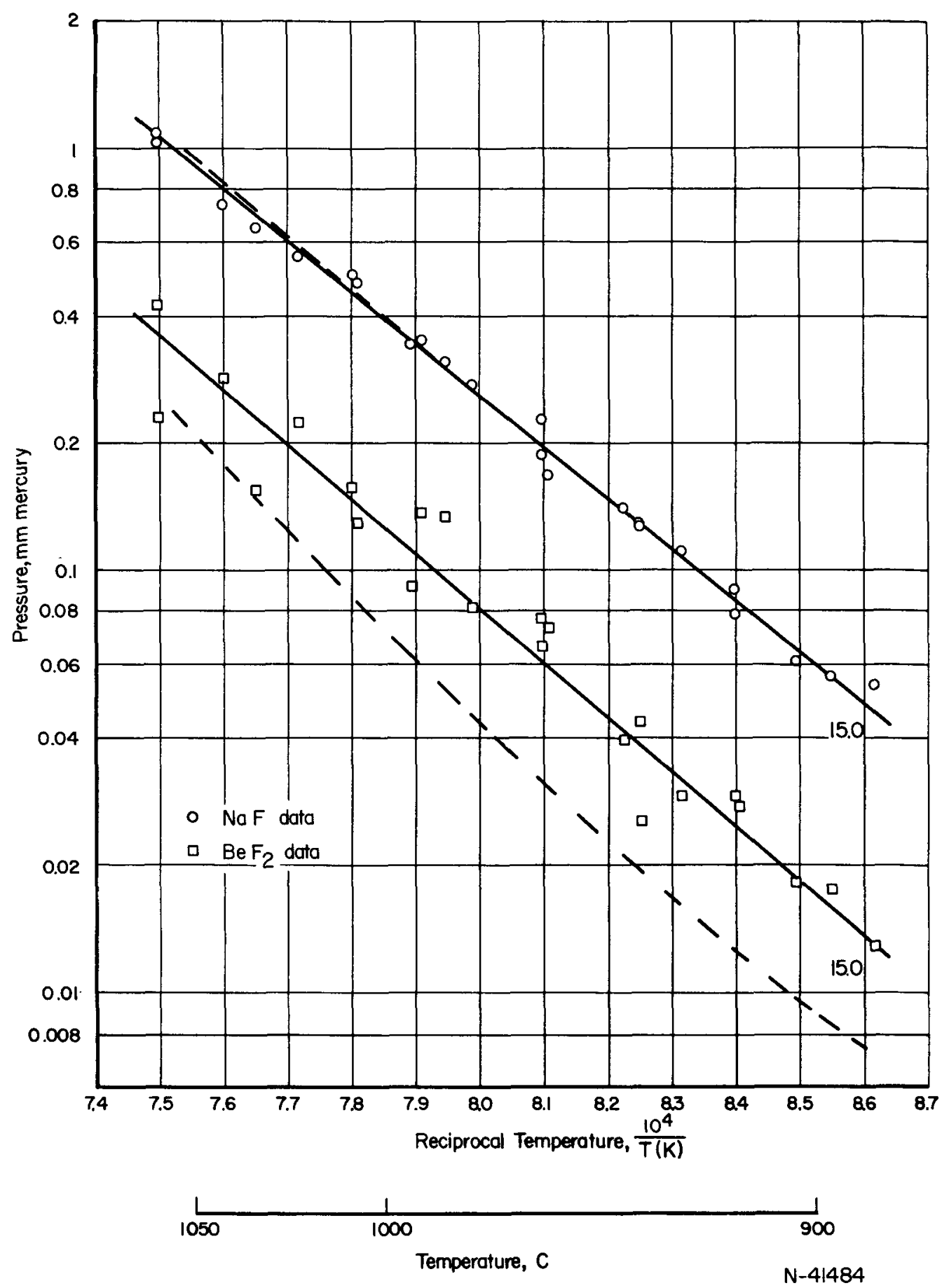

FIGURE 7. DATA FOR 15 MOLE PER CENT BeF 2 COMPOSITION Interpretation of solid and dashed curves is the same as that given in Figures 4 and 5. 
TABLE 3. VAPOR-PRESSURE DATA OF THE NaF-BeF 2 SYSTEM

\begin{tabular}{|c|c|c|c|}
\hline $\begin{array}{c}\text { Temperature, } \\
\mathrm{C} \\
\end{array}$ & $\begin{array}{c}\text { Observed pNaF, } \\
\text { mm mercury }\end{array}$ & $\begin{array}{c}\text { Observed } \mathrm{pBeF}_{2} \text {, } \\
\text { mm mercury }\end{array}$ & $\begin{array}{l}\text { Flow Rate of } \\
\text { Carrier Gas, } \\
\mathrm{cm}^{3} \text { per min }\end{array}$ \\
\hline \multicolumn{4}{|c|}{15.0 Mole Per Cent BeF2 } \\
\hline 1061 & 1.082 & 0.43 & 40.1 \\
\hline 1060 & 1.039 & 0.23 & 40.2 \\
\hline 1043 & 0.742 & 0.29 & 40.0 \\
\hline 1034 & 0.656 & 0.15 & 37.9 \\
\hline 1023 & 0.563 & 0.22 & 37.3 \\
\hline 1009 & 0.499 & 0.16 & 41.6 \\
\hline 1008 & 0.485 & 0.13 & 35.7 \\
\hline 993.8 & 0.345 & 0.092 & 39.3 \\
\hline 991.4 & 0.353 & 0.14 & 39.3 \\
\hline 985.2 & 0.314 & 0.14 & 51.4 \\
\hline 978.7 & 0.277 & 0.082 & 49.4 \\
\hline 961.8 & 0.229 & 0.066 & 47.4 \\
\hline 961.8 & 0.189 & 0.078 & 49.5 \\
\hline 960.4 & 0.169 & 0.074 & 52.8 \\
\hline 942.6 & 0.140 & 0.040 & 50.1 \\
\hline 939.0 & 0.128 & 0.044 & 51.3 \\
\hline 938.9 & 0.130 & 0.026 & 50.9 \\
\hline 929.9 & 0.112 & 0.029 & 45.4 \\
\hline 917.3 & 0.0906 & 0.029 & 50.4 \\
\hline 917.3 & 0.0797 & 0.029 & 49.2 \\
\hline 903.8 & 0.0609 & 0.018 & 51.6 \\
\hline 896.6 & 0.0567 & 0.018 & 50.7 \\
\hline 887.0 & 0.0540 & 0.013 & 50.8 \\
\hline \multicolumn{4}{|c|}{ 19. 2 Mole Per Cent $\mathrm{BeF}_{2}$} \\
\hline 1060 & 1.189 & 0.472 & 44.4 \\
\hline 1051 & 1.018 & 0.334 & 39.8 \\
\hline 1043 & 0.848 & 0.291 & 47.0 \\
\hline 1026 & 0.619 & 0.205 & 47.1 \\
\hline 1009 & 0.459 & 0.152 & 51.7 \\
\hline 992.6 & 0.345 & 0.136 & 47.8 \\
\hline 977.1 & 0.246 & 0.0640 & 50.6 \\
\hline 961.4 & 0.208 & 0.0647 & 50.0 \\
\hline 947.4 & 0.142 & 0.0404 & 51.2 \\
\hline 931.6 & 0.0971 & 0.0278 & 50.2 \\
\hline 917.6 & 0.0824 & 0.0227 & 50.2 \\
\hline 903.3 & 0.0848 & 0.0168 & 49.8 \\
\hline 896.4 & 0.0530 & 0.0148 & 49.6 \\
\hline 890.7 & 0.0449 & 0.0142 & 51.4 \\
\hline
\end{tabular}


TABLE 3. (Continued)

\begin{tabular}{|c|c|c|c|}
\hline $\begin{array}{c}\text { Temperature, } \\
\mathrm{C} \\
\end{array}$ & $\begin{array}{c}\text { Observed pNaF, } \\
\text { mm mercury }\end{array}$ & $\begin{array}{c}\text { Observed } \mathrm{pBeF}_{2} \text {, } \\
\text { mm mercury }\end{array}$ & $\begin{array}{l}\text { Flow Rate of } \\
\text { Carrier Gas, } \\
\mathrm{cm}^{3} \text { per min }\end{array}$ \\
\hline \multicolumn{4}{|c|}{ 24. 5 Mole Per Cent $\mathrm{BeF}_{2}$} \\
\hline 1035 & 0.915 & 0.453 & 47.5 \\
\hline 1025 & 0.736 & 0.467 & 49.9 \\
\hline 1021 & 0.636 & 0.372 & 47.9 \\
\hline 996.4 & 0.437 & 0.260 & 49.1 \\
\hline 992.6 & 0.414 & 0.286 & 49.2 \\
\hline 976.7 & 0.292 & 0.179 & 43.5 \\
\hline 963.3 & 0.247 & -- & 47.3 \\
\hline 961.4 & 0.220 & 0.145 & 47.8 \\
\hline 947.0 & 0.171 & 0.102 & 48.7 \\
\hline 946.4 & 0.181 & -- & 47.2 \\
\hline 932.9 & 0.133 & -- & 49.3 \\
\hline 932.0 & 0.129 & 0.0755 & 48.9 \\
\hline 926.7 & 0.114 & 0.0550 & 49.6 \\
\hline 921.8 & 0.103 & 0.0438 & 51.3 \\
\hline 916.7 & 0.0981 & 0.0527 & 48.8 \\
\hline 910.0 & 0.0747 & 0.0356 & 47.2 \\
\hline 909.5 & 0.0912 & -- & 15.2 \\
\hline 897.8 & 0.0620 & 0.0327 & 49.2 \\
\hline 893.1 & 0.0607 & 0.0289 & 51.0 \\
\hline 882.9 & 0.0486 & 0.0194 & 48.5 \\
\hline 876.2 & 0.0431 & -- & 48.9 \\
\hline 867.1 & 0.0381 & 0.0202 & 48.4 \\
\hline 856.8 & 0.0280 & 0.0128 & 50.8 \\
\hline 836.0 & 0.0188 & -- & 48.0 \\
\hline 825.6 & 0.0125 & 0.00635 & 51.2 \\
\hline \multicolumn{4}{|c|}{31.5 Mole Per Cent BeF 2} \\
\hline 1060 & 2.91 & 2.40 & 23.7 \\
\hline 1060 & 2.41 & 2.19 & 22.6 \\
\hline 1043 & 1.64 & 2.09 & 25.4 \\
\hline 1043 & 1.67 & 1.99 & 25.7 \\
\hline 1026 & 1.72 & 1.50 & 31.1 \\
\hline 1026 & 1.30 & 1.72 & 25.1 \\
\hline 1009 & 0.851 & 0.891 & 50.3 \\
\hline 992.6 & 0.671 & 0.612 & 43.4 \\
\hline 992.5 & 0.739 & 0.654 & 48.2 \\
\hline 979.0 & 0.539 & 0.497 & 49.7 \\
\hline 977.5 & 0.485 & 0.450 & 49.3 \\
\hline 969.0 & 0.459 & 0.229 & 50.3 \\
\hline 961.4 & 0.401 & 0.279 & 49.5 \\
\hline 961.3 & 0.366 & 0.159 & 49.7 \\
\hline 946.1 & 0.292 & 0.228 & 48.7 \\
\hline 931.7 & 0.226 & 0.0667 & 48.2 \\
\hline 931.6 & 0.224 & 0.190 & 53.8 \\
\hline 917.5 & 0.165 & 0.117 & 51.0 \\
\hline 916.9 & 0.160 & 0.0984 & 50.7 \\
\hline
\end{tabular}


TABLE 3. (Continued)

\begin{tabular}{|c|c|c|c|}
\hline $\begin{array}{c}\text { Tempe rature, } \\
\text { C }\end{array}$ & $\begin{array}{l}\text { Observed pNaF, } \\
\text { mm mercury }\end{array}$ & $\begin{array}{c}\text { Observed pBeF } 2, \\
\text { mm mercury }\end{array}$ & $\begin{array}{l}\text { Flow Rate of } \\
\text { Carrier Gas } \\
\mathrm{cm}^{3} \text { per min }\end{array}$ \\
\hline \multicolumn{4}{|c|}{31.5 Mole Per Cent BeF 2 (Continued) } \\
\hline 903.3 & 0.114 & 0.0577 & 49.2 \\
\hline 903.3 & 0.115 & 0.0735 & 49.0 \\
\hline 889.8 & 0.0907 & 0.0685 & 50.7 \\
\hline 876.2 & 0.0689 & 0.0555 & 49.4 \\
\hline 876.2 & 0.0698 & 0.0117 & 43.7 \\
\hline \multicolumn{4}{|c|}{ 39. 5 Mole Per Cent $\mathrm{BeF}_{2}$} \\
\hline 1026 & 2.52 & 3.56 & 21.0 \\
\hline 1010 & 2.05 & 3.35 & 21.8 \\
\hline 994.2 & 1.52 & 2.28 & 21.5 \\
\hline 978.5 & 1.15 & 1.99 & 21.9 \\
\hline 961.4 & 0.950 & 1.34 & 26.5 \\
\hline 946.9 & 0.672 & 1.02 & 33.5 \\
\hline 917.3 & 0.399 & 0.616 & 47.3 \\
\hline 896.3 & 0.257 & 0.409 & 48.5 \\
\hline 876.2 & 0.166 & 0.240 & 49.0 \\
\hline 855.4 & 0.113 & 0.189 & 48.1 \\
\hline \multicolumn{4}{|c|}{ 50. 0 Mole Per Cent BeF 2} \\
\hline 1012 & 3.35 & 16.0 & 19.5 \\
\hline 996.8 & 2.73 & 14.1 & 16.3 \\
\hline 987.0 & 2.70 & 13.6 & 14.2 \\
\hline 983.2 & 2.20 & 12.3 & 15.4 \\
\hline 975.6 & 1.82 & 8.53 & 44.6 \\
\hline 970.7 & 2.01 & 9.68 & 13.4 \\
\hline 961.4 & 1.61 & 8.85 & 15.4 \\
\hline 956.6 & 1.23 & 6.57 & 29.8 \\
\hline 932.0 & 0.952 & 5.71 & 24.2 \\
\hline 918.3 & 0.677 & 3.89 & 30.4 \\
\hline 916.1 & 0.727 & 3.71 & 18.9 \\
\hline 895.3 & 0.450 & 2.72 & 26.8 \\
\hline 877.9 & 0.312 & 1.90 & 34.1 \\
\hline 854.4 & 0.191 & 1.27 & 41.0 \\
\hline 833.5 & 0.130 & 0.804 & 47.5 \\
\hline 815.1 & 0.0779 & 0.548 & 50.0 \\
\hline 796.5 & 0.0547 & 0.367 & 49.7 \\
\hline \multicolumn{4}{|c|}{ 58. 8 Mole Per Cent $\mathrm{BeF}_{2}$} \\
\hline 988.6 & 2.26 & 30.3 & 15.8 \\
\hline 963.1 & 1.505 & 20.5 & 12.2 \\
\hline 938.8 & 0.993 & 14.25 & 15.0 \\
\hline 919.4 & 0.674 & 9.61 & 22.4 \\
\hline 896.4 & 0.477 & 6.03 & 26.4 \\
\hline 877.7 & 0.292 & 4.71 & 31.1 \\
\hline 856.8 & 0.198 & 3.07 & 33.3 \\
\hline 840.3 & 0.131 & 2.24 & 50.8 \\
\hline
\end{tabular}


TABLE 3. (Continued)

\begin{tabular}{|c|c|c|c|}
\hline $\begin{array}{c}\text { Temperature, } \\
\mathrm{C}\end{array}$ & $\begin{array}{c}\text { Observed pNaF, } \\
\text { mm mercury }\end{array}$ & $\begin{array}{c}\text { Observed pBeF } 2, \\
\text { mm mercury }\end{array}$ & $\begin{array}{l}\text { Flow Rate of } \\
\text { Carrier Gas, } \\
\mathrm{cm}^{3} \text { per min }\end{array}$ \\
\hline \multicolumn{4}{|c|}{ 58.8 Mole Per Cent BeF2 (Continued) } \\
\hline 819.8 & 0.0855 & 1.43 & 50.5 \\
\hline 802.2 & 0.0556 & 0.980 & 50.4 \\
\hline \multicolumn{4}{|c|}{ 73. 9 Mole Per Cent BeF 2} \\
\hline 976.9 & 1.36 & 48.5 & 13.7 \\
\hline 956.0 & 0.851 & 37.2 & 13.9 \\
\hline 937.0 & 0.684 & 23.6 & 19.7 \\
\hline 910.3 & 0.372 & 15.0 & 21.9 \\
\hline 890.2 & 0.248 & 10.1 & 22.3 \\
\hline 871.0 & 0.170 & 7.67 & 26.5 \\
\hline 850.4 & 0.108 & 4.63 & 30.2 \\
\hline 833.4 & 0.0712 & 3.62 & 37.8 \\
\hline 813.7 & 0.0512 & 2.32 & 37.2 \\
\hline 800.6 & 0.0324 & 1.74 & 43.3 \\
\hline 784.9 & 0.0234 & 1.18 & 50.3 \\
\hline 768.5 & 0.0104 & 0.785 & 50.8 \\
\hline 752.5 & 0.00817 & 0.482 & 50.6 \\
\hline 736.8 & 0.00415 & 0.357 & 50.6 \\
\hline 726.7 & 0.00422 & 0.288 & 49.4 \\
\hline $717: 9$ & 0.00602 & 0.232 & 49.9 \\
\hline 688.3 & 0.00158 & 0.110 & 50.0 \\
\hline 670.2 & 0.00106 & 0.0635 & 49.8 \\
\hline 657.4 & 0.00167 & 0.0483 & 49.4 \\
\hline 635.7 & -- & 0.0196 & 51.0 \\
\hline 625.8 & -- & 0.0101 & 50.2 \\
\hline 604.0 & - & 0.00801 & 50.1 \\
\hline 595.7 & -- & 0.00526 & 50.4 \\
\hline 574.3 & -- & 0.00183 & 51.1 \\
\hline 566.5 & -- & 0.00192 & 51.0 \\
\hline 539.8 & -- & 0.000794 & 50.2 \\
\hline 534.5 & -- & 0.000823 & 51.0 \\
\hline 514.3 & -- & 0.00132 & 50.4 \\
\hline 509.2 & -- & 0.000555 & 50.6 \\
\hline 490.2 & -- & $<0.000536$ & 50.6 \\
\hline 488.1 & -- & $<0.000564$ & 50.2 \\
\hline
\end{tabular}




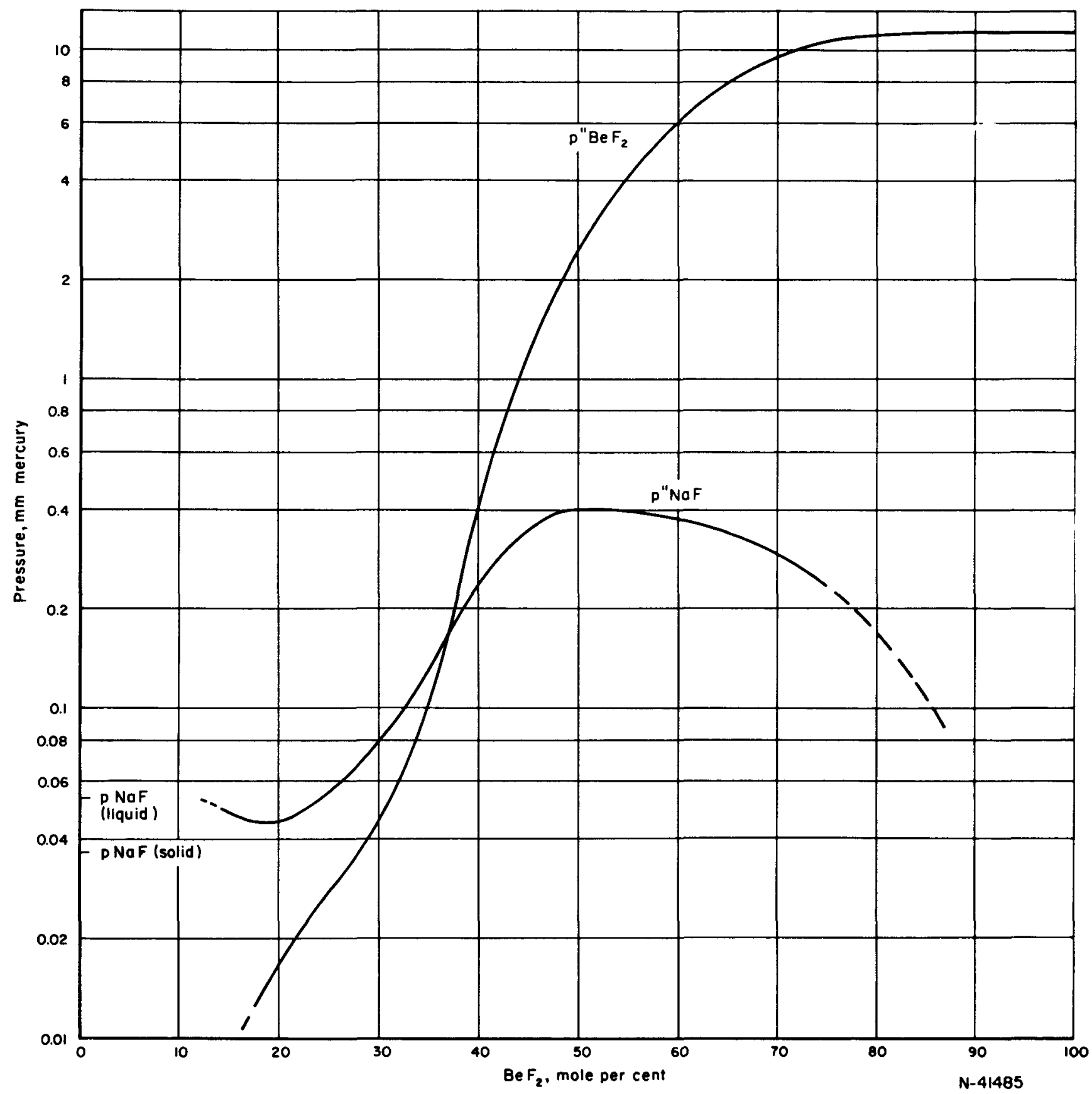

FIGURE 8. PARTIAL PRESSURES OF NaF AND Be $F_{2}$ FOR NaF-BeF 2 SYSTEM AT $890 \mathrm{C}$ ON THE BASIS THAT ONLY NaF AND BeF 2 EXIST IN VAPOR PHASE 


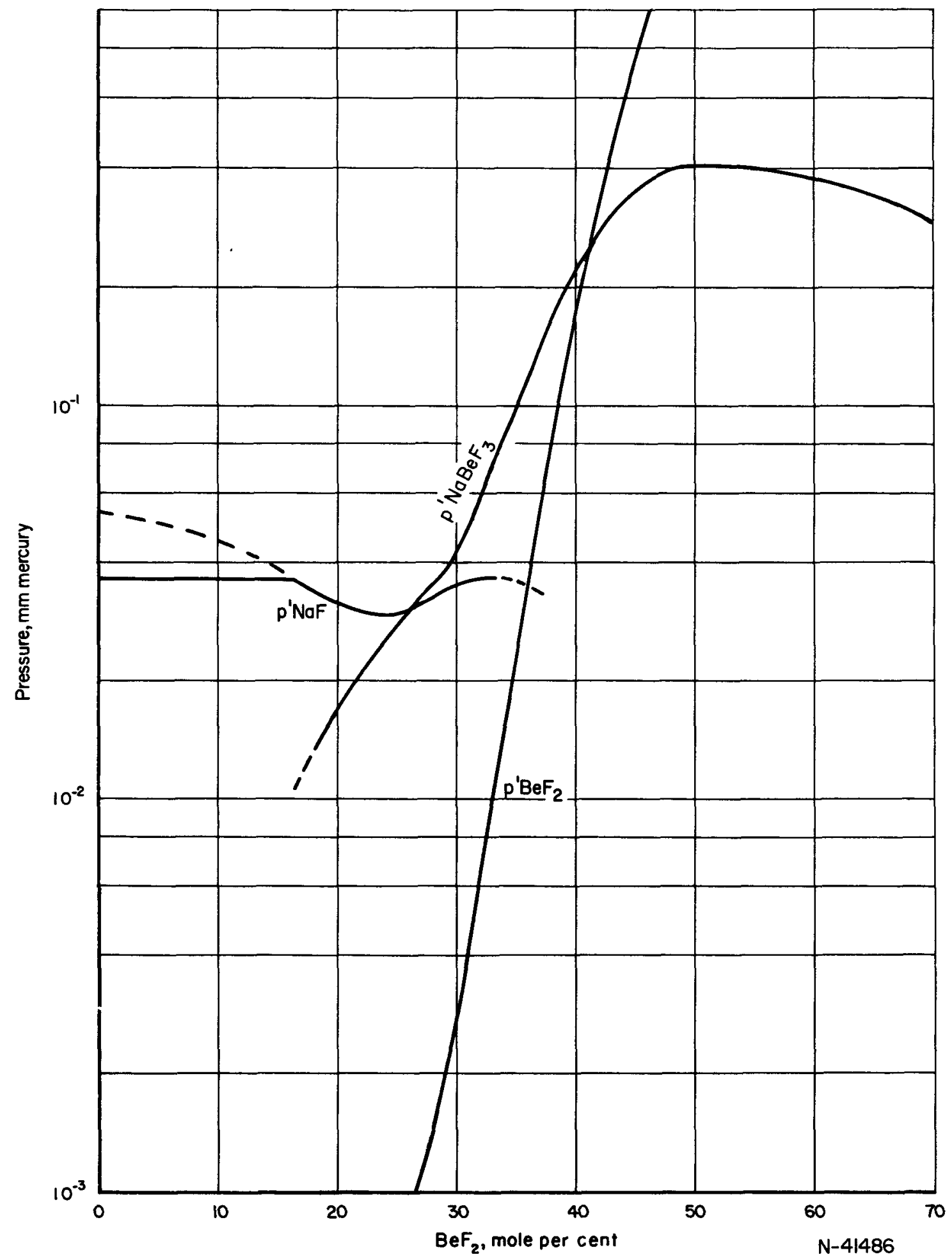

FIGURE 9. PARTIAL PRESSURES AT $890 \mathrm{C}$ ON THE BASIS THAT NaF, $\mathrm{BeF}_{2}$, AND $\mathrm{NaBeF}_{3}$ EXIST IN VAPOR PHASE 
Construction of partial-pressure plots such as that shown in Figure 10 at $932 \mathrm{C}$ indicates that this p' NaF peak becomes less prominent as the temperature is increased until finally it disappears. The explanation is postulated that the complex $\mathrm{Na}_{2} \mathrm{BeF}_{4}$ is rather unstable and dissociates readily into $\mathrm{NaF}$ and $\mathrm{NaBeF}_{3}$ as the temperature is increased.

Having postulated that the vapor phase consists of $\mathrm{Na}_{2} \mathrm{BeF}_{4}$ in addition to $\mathrm{NaF}$, $\mathrm{BeF}_{2}$, and $\mathrm{NaBeF} 3$, the next problem is the determination of the partial pressure of $\mathrm{Na}_{2} \mathrm{BeF}_{4}$. The determination of $\mathrm{p}^{\prime} \mathrm{NaBeF}_{3}$ was relatively simple because virtually all of the $\mathrm{NaF}$ was tied up in the complex $\mathrm{NaBeF}_{3}$; therefore, the peak of the $\mathrm{p}^{\prime \prime} \mathrm{NaF}$ curve could be taken to be very nearly that of the $\mathrm{p}^{\prime} \mathrm{NaBeF}_{3}$ curve. That the same simple situation does not exist for $\mathrm{Na}_{2} \mathrm{BeF}_{4}$ is evident from a study of Figure 9. The chief difficulty is that at $33-1 / 3 \mathrm{mpc}$ the three molecular species which contain sodium atoms, $\mathrm{NaF}, \mathrm{NaBeF}_{3}$, and $\mathrm{Na}_{2} \mathrm{BeF}_{4}$, appear to exert vapor pressures having the same order of magnitude. It is clear that in order to solve the problem other helpful relations have to be called upon. In the vapor phase we have these basic reactions:

$$
\begin{gathered}
\mathrm{NaBeF}_{3}(\mathrm{~g})=\mathrm{NaF}(\mathrm{g})+\mathrm{BeF}_{2}(\mathrm{~g}) \\
\mathrm{Na}_{2} \mathrm{BeF}_{4}(\mathrm{~g})=\mathrm{NaF}(\mathrm{g})+\mathrm{NaBeF}_{3}(\mathrm{~g}) .
\end{gathered}
$$

From these, the following equilibrium constants are obtained:

$$
\begin{gathered}
\mathrm{K}_{1} \propto \frac{(\mathrm{pNaF})\left(\mathrm{pBeF}_{2}\right)}{(\mathrm{pNaBeF} 3)} \\
\mathrm{K}_{2}=\frac{(\mathrm{pNaF})\left(\mathrm{pNaBeF}_{3}\right)}{\left(\mathrm{pNa}_{2} \mathrm{BeF}_{4}\right)} \\
\mathrm{K}_{3}=\frac{\mathrm{K}_{1}}{\mathrm{~K}_{2}}=\frac{\left(\mathrm{pBeF}_{2}\right)\left(\mathrm{pNa}_{2} \mathrm{BeF}_{4}\right)}{\left(\mathrm{pNaBeF}_{3}\right)^{2}} .
\end{gathered}
$$

Only two of these equilibrium constants are, of course, independent.

Results obtained with the transpiration apparatus are based only on the number of moles of $\mathrm{NaF}$ and $\mathrm{BeF}_{2}$ present in the condenser without regard to complexes formed. The resulting equations are:

$$
\begin{aligned}
& \mathrm{N}_{\mathrm{NaF}}=\mathrm{nNaF}+\mathrm{nNaBeF}_{3}+2 \mathrm{nNa}_{2} \mathrm{BeF}_{4} \\
& \mathrm{~N}_{\mathrm{BeF}_{2}}=\mathrm{nBeF}_{2}+\mathrm{nNaBeF}_{3}+\mathrm{nNa}_{2} \mathrm{BeF}_{4},
\end{aligned}
$$

where $\mathrm{N}_{\mathrm{NaF}}$ and $\mathrm{N}_{\mathrm{BeF}}$ are the moles of $\mathrm{NaF}$ and $\mathrm{BeF}_{2}$, respectively, in the condenser regardless of complexes formed, and $n$ represents the moles of the particular molecular species. Since pon for partial pressures of the order of $10 \mathrm{~mm}$ mercury or less**, we have

\footnotetext{
"Because of its frequency of occurrence, the phrase "mole per cent BeF 2 composition" has been abbreviated to "mpc".
}

- See Appendix of Reference (1). 


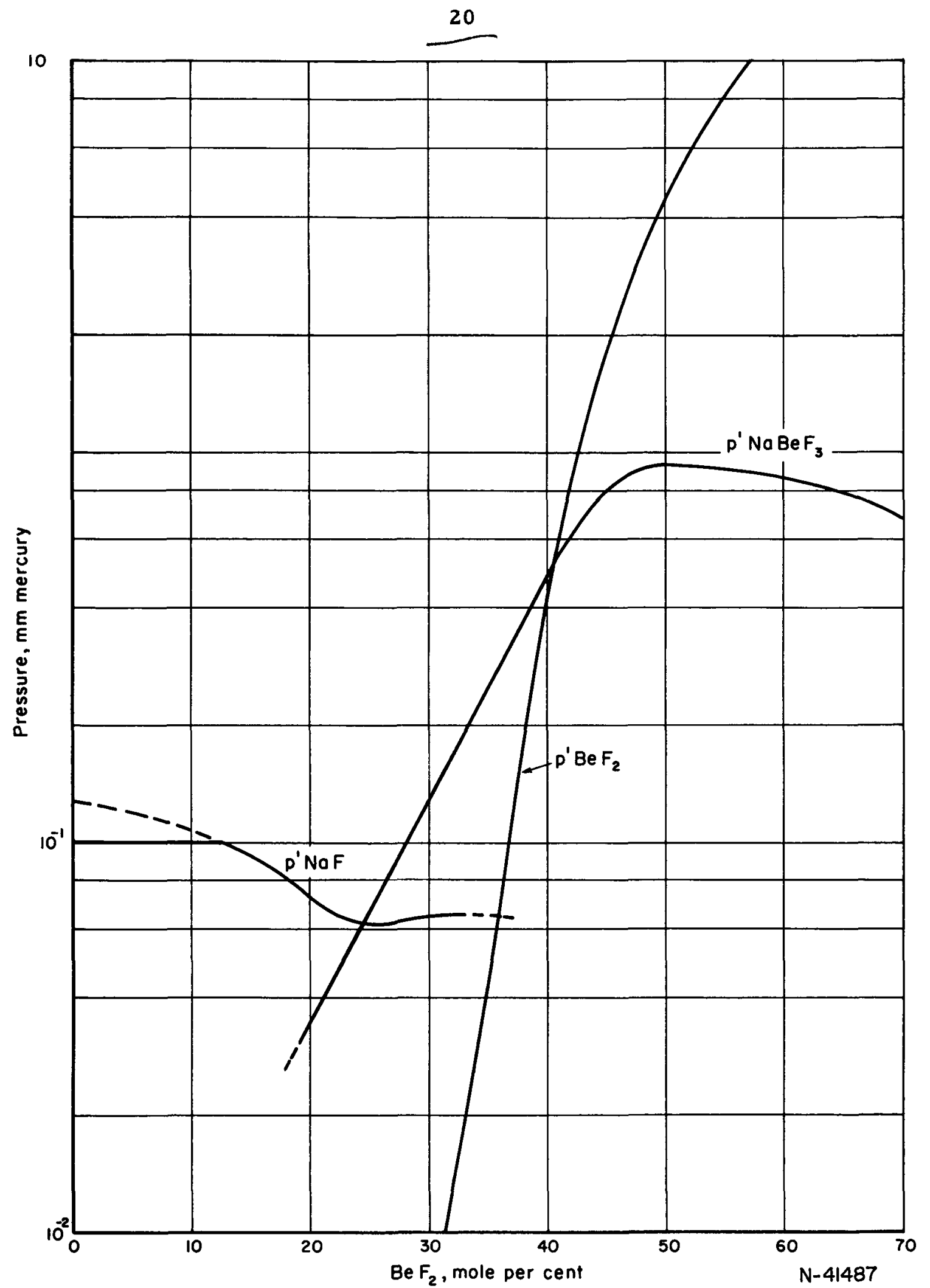

FIGURE 10. PARTIAL PRESSURES AT $932 \mathrm{C}$ ON THE BASIS THAT NaF, BeF 2 , AND $\mathrm{NaBeF}_{3}$ EXIST IN VAPOR PHASE 


$$
\begin{gathered}
p^{\prime \prime N a F}=\mathrm{pNaF}+\mathrm{pNaBeF}_{3}+2 \mathrm{pNa}_{2} \mathrm{BeF}_{4} \\
\mathrm{p}^{\prime \prime B e F}{ }_{2}=\mathrm{pBeF}_{2}+\mathrm{pNaBeF}_{3}+\mathrm{pNa}_{2} \mathrm{BeF}_{4} .
\end{gathered}
$$

Another helpful relation would be

$$
\text { Total pressure }=\mathrm{pNaF}+\mathrm{pBeF}_{2}+\mathrm{pNaBeF}_{3}+\mathrm{pNa}_{2} \mathrm{BeF}_{4} .
$$

For sufficiently low pressures, Equations (14), (15), and (16) could be used simultaneously. It must be pointed out, however, that (16) would be of little value where one or two components exert a much larger vapor pressure than do the other components. In any event, for Equation (16) to be of any value, the total pressure would have to be determined very accurately.

Since no direct experimental information was available on either the total pressure of the system or the equilibrium constants, only two equations remained, with four unknowns. Hence, the system could not be solved explicitly in terms of the partial pressures of the various components. However, rather than leave the system indeterminate, efforts were made to obtain an approximate solution by reasonable estimates and successive approximations.

Estimation of Partial Pressures by Approximation Methods

An analysis of the partial pressures of the various vapor-phase components was limited to the 890 to $1050 \mathrm{C}$ range since this was the limit of the temperature range over which data were available for almost all compositions of the difficult NaF-rich region. The first step in resolving this region was to approximate, from available information, the partial pressures of $\mathrm{NaF}$ as a function of temperature for the 15.0, $19.2,24.5$, and $31.5 \mathrm{mpc}^{\prime} \mathrm{s}$. It was indicated above that, for a vapor phase assumed to consist only of $\mathrm{NaF}, \mathrm{BeF}_{2}$, and $\mathrm{NaBeF}_{3}$, the $\mathrm{p}^{\prime} \mathrm{NaF}$ peak which is evident in Figure 9 disappears in pressure-composition plots constructed at higher temperatures. The interpretation was that $\mathrm{Na}_{2} \mathrm{BeF}_{4}$ is unstable and dissociates readily into $\mathrm{NaF}$ and $\mathrm{NaBeF}$ 3. Hence, for high-temperature pressure-composition plots the $\mathrm{p}^{\prime} \mathrm{NaF}$ and pNaF curves should be nearly coincidental in the NaF-rich region. Using this result, the $\mathrm{pNaF}^{\prime} \mathrm{s}$ were estimated for the $15.0,19.2,24.5$, and $31.5 \mathrm{mpc}$ 's at $1017 \mathrm{C}$. The NaF$\mathrm{BeF}_{2}$ phase diagrams by Thilo and $S$ chröder(3) aided in the determination of $\mathrm{pNaF}$ for $15 \mathrm{mpc}$ at $890 \mathrm{C}$, the lower limit of the temperature range. According to that diagram the melting point of this particular composition is very nearly $890 \mathrm{C}$. By use of Equation (4), pNaF at this composition and temperature was calculated to be $0.036 \mathrm{~mm}$ of mercury. The slopes of the $\log \mathrm{pNaF}$ vs. $\frac{1}{\mathrm{~T}}$ curve for $15 \mathrm{mpc}$ and for pure liquid $\mathrm{NaF}$ turned out to be nearly the same. It was then assumed that the slopes of the log pNaF vs. $\frac{1}{T}$ curves were nearly the same for the 0 to $31.5 \mathrm{mpc}$ region. This result used together with the pNaF estimates for various compositions at $1017 \mathrm{C}$ gave pNaF estimates for compositions at $890 \mathrm{C}$. Having obtained this estimate, the number of unknowns for Equations (14) and (15) was reduced from 4 to 3 for the 15.0, 19.2, 24.5, and $31.5 \mathrm{mpc}^{\prime} \mathrm{s}$. 
The partial pressures $\mathrm{pNaBeF}_{3}, \mathrm{pBeF}_{2}$, and $\mathrm{pNa}_{2} \mathrm{BeF}_{4}$ were then estimated for the various compositions and temperatures in such a manner that (a) the resulting $\log$ p" vs. $\frac{1}{T}$ curves provided the best fit through the experimental points given in Figures 4 , 5,6 , and 7 and (b) the $\log \mathrm{Kp}$ vs. $\frac{\mathrm{l}}{\mathrm{T}}$ curves obtained from these partial pressures yielded reasonable $\Delta S^{\circ}$ values for the Reactions (7) and (8). Condition (a) was not easy to satisfy because the scatter of the experimental points for some compositions was such that it was difficult to decide on the best curve through these points. The estimated partial pressures which seemed to satisfy Condition (a) were then used to calculate the equilibrium constants given in Equations (9) and (10) for the various compositions and temperatures. The logarithms of the equilibrium constants, $\mathrm{K}_{\mathrm{i}} \mathrm{P}$, were then plotted as functions of $\frac{1}{\mathrm{~T}}$ and the best straight lines drawn through these points. From these plots equations of the type

$$
\log \mathrm{Kp}=\mathrm{A}+\frac{\mathrm{B}}{\mathrm{T}}
$$

were obtained for Reactions (7) and (8). By means of relations

$$
\frac{\mathrm{d} \ln \mathrm{Kp}_{\mathrm{p}}}{\mathrm{dT}}=\frac{\Delta \mathrm{H}^{\circ}}{\mathrm{RT}^{2}}
$$

and

$$
\Delta \mathrm{F}^{\mathrm{O}}=-\mathrm{RT} \ln \mathrm{Kp}
$$

Values of $\Delta \mathrm{S}^{\circ}$ values were obtained for these reactions by substitution in the equation

$$
\Delta S^{\circ}=\frac{\Delta H^{\circ}-\Delta F^{\circ}}{T}
$$

To satisfy Condition (b), the $\log \mathrm{Kp}$ vs. $\frac{1}{\mathrm{~T}}$ curves were so adjusted as to yield reasonable $\Delta S^{0}$ values while still satisfying Condition (a). The extent to which Condition (a) was satisfied is apparent from the fit of the dashed curves with the experimental points given in Figures $4,5,6$, and 7 . The poorest fit is manifestly that of $\mathrm{p}^{\prime \prime B e F} 2$ for $15.0 \mathrm{mpc}$ (Figure 7). However, an effort to correct this situation led to other changes which resulted in a less satisfactory over-all solution. It is interesting to observe that, in general, the best fit was obtained for those compositions whose experimental values showed the least scatter.

The efforts to satisfy Condition (b) and Condition (a) simultaneously produced these results:

For the reaction

$$
\mathrm{NaBeF}_{3}(\mathrm{~g})=\mathrm{NaF}(\mathrm{g})+\mathrm{BeF}_{2}(\mathrm{~g})
$$

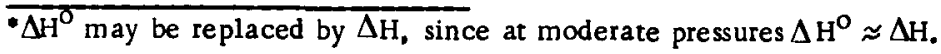


the re was obtained

$$
\begin{gathered}
\log K_{1} p=6.67-\frac{14.66 \times 10^{3}}{T(K)} \\
\Delta H=67.1 \mathrm{kcal} \text { per } \mathrm{g}-\mathrm{mole} \\
\Delta S_{1300 \mathrm{~K}}^{0}=30.5 \mathrm{e.u} .
\end{gathered}
$$

For the reaction

$$
\mathrm{Na}_{2} \mathrm{BeF}_{4}(\mathrm{~g})=\mathrm{NaF}(\mathrm{g})+\mathrm{NaBeF}_{3}(\mathrm{~g}),
$$

there resulted

$$
\begin{gathered}
\log \mathrm{K}_{2} \mathrm{p}=14.11-\frac{21.89 \times 10^{3}}{\mathrm{~T}(\mathrm{~K})} \\
\Delta \mathrm{H}=100 \mathrm{kcal} \text { per } \mathrm{g}-\mathrm{mole}, \\
\Delta \mathrm{S}_{1300 \mathrm{~K}}^{\circ}=64.6 \mathrm{e} . \mathrm{u} .
\end{gathered}
$$

The $\Delta S^{0}$ value for Reaction (7) seems to be reasonable. The fact that $\Delta S^{0}$ is rather high for Reaction (8) is due in part to the large $\Delta H$ value. This large $\Delta H$ value is the result of the rather rapid dissociation of $\mathrm{Na}_{2} \mathrm{BeF}_{4}$ as the temperature is increased. This is the type of behavior that might be expected, for while $\mathrm{NaBeF}_{3}$ should form rather stable tetrahedral bonding, no such stable bonding is evident for $\mathrm{Na}_{2} \mathrm{BeF}_{4}$.

The discussion so far has led to the determination of $\log p$ vs. $\frac{1}{\mathrm{~T}}$ curves for the 15. 0, 19.2, 24.5, and 31.5 mpc's as well as Kp-T Equations (21) and (24), which hold for the entire $\mathrm{NaF}-\mathrm{BeF}_{2}$ system. By using Equations (21) and (24), it was then not difficult to determine the $\log p$ vs. $\frac{1}{T}$ curves of the various components for the 39.5 , $50.0,58.8$, and $73.9 \mathrm{mpc}^{\prime} \mathrm{s}$. Since for these compositions

$$
\begin{gathered}
\mathrm{pNaF}<\mathrm{pNa}_{2} \mathrm{BeF}_{4}<<\mathrm{pNaBeF}_{3} \\
\mathrm{pNa}_{2} \mathrm{BeF}_{4}<<\mathrm{pBeF}_{2},
\end{gathered}
$$

there resulted

$$
\begin{gathered}
\mathrm{pNaBeF}_{3} \approx \mathrm{p}^{\prime} \mathrm{NaBeF}_{3} \\
\mathrm{pBeF}_{2} \approx \mathrm{p}^{\prime} \mathrm{BeF}_{2} .
\end{gathered}
$$

Hence, the partial pressures of the various components could be obtained for these compositions by repeated applications of Equations (9), (10), and (11), together with Equations (14) and (15).

Thus a set of partial pressures was derived over 890 to $1050 \mathrm{C}$ for the $\mathrm{NaF}-\mathrm{BeF}_{2}$ system which was self-consistent with the equilibrium constants given in Equation (9) and (10) simultaneously, the logarithms of the partial pressures and the equilibrium constants varying smoothly and linearly with $\frac{l}{T}$ in that temperature range. 
Figures 11 and 12 show how the partial pressures of the vapor-phase components vary with composition for two temperatures. These plots bear a superficial resemblance to the usual liquid-solid phase diagrams in that the location of the peak of a curve indicates the presence of a complex and gives its composition. A tabulation of all the derived constants of the partial-pressure equations for $\mathrm{NaF}_{2} \mathrm{BeF}_{2}, \mathrm{NaBeF}_{3}$, and $\mathrm{Na}_{2} \mathrm{BeF}_{4}$ is given in Table 4 .

Recent findings by Miller and Kusch(4) show the gaseous phase to be even more complex. From a measurement of the velocity distribution of molecules in a beam produced by $\mathrm{NaF}$ vapor effusing through a small slit, they were able to determine the concentration of dimers and trimers in the $\mathrm{NaF}$ vapor phase. Results obtained by them over the 842 to $916 \mathrm{C}$ temperature range indicated a concentration of polymers in the vapor phase sufficiently great to lower the results obtained from the transpiration method by about 10 per cent. However, since their findings showed the concentration of dimers and trimers to be temperature dependent, and since the upper temperature limit of Battelle's studies extended some $130 \mathrm{C}$ beyond theirs, no vapor-pressure corrections were made for $\mathrm{NaF}$. In any event, if data on dimers and trimers were available over this temperature range, the resulting changes would be expected to be relatively minor.

Derived Phase Diagram

Using the results given in Table 4, a phase diagram, Figure 13, was constructed for the $\mathrm{NaF}-\mathrm{BeF}_{2}$ system at a pressure of $1 \mathrm{~mm}$ of mercury. The composition of the azeotrope was found to be pressure dependent. The peculiar-looking indentation of the vapor-composition curve is quite real. It stems from the fact that the complex $\mathrm{NaBeF} 3$ exerts an appreciable partial pressure. This dip occurs even when the construction of this phase diagram is based on the assumption that only $\mathrm{NaF}$ and $\mathrm{BeF}_{2}$ molecules exist in the vapor phase. Hence, the presence of a dip in the vapor-composition curve indicates the existence of a molecular complex in the vapor phase. The prominence of this dip bears a relationship to the vapor pressure of this complex. Of course, if the othe $r$ components exert vanishingly small partial pressures at the composition indicated by the partial-pressure peak of the complex, the vapor phase would have the same composition as the liquid phase, and the liquid-and vapor-composition curves would meet.

Total Vapor Pressures of the NaF-BeF 2 System

Figure 14 shows how the total pressure of the $\mathrm{NaF}-\mathrm{BeF}_{2}$ system varies with composition for two temperatures. The behavior of the lower temperature vaporpressure curve in the high-NaF-composition region is explained by the fact that the solid NaF phase is present over the 0 to $15 \mathrm{mpc}$ range (see Figure 11). While pNaF remains constant over that composition region, the other partial pressures increase as the composition becomes richer in $\mathrm{BeF}_{2}$. Beyond $15 \mathrm{mpc}$, the liquid phase begins and the pNaF starts to drop. Since pNaF is greater at that point than the sum of the other partial pressures, the total pressure decreases until about $19 \mathrm{mpc}$ is reached. From that point on the other partial pressures predominate, resulting in an increase in the total vapor pressure. 


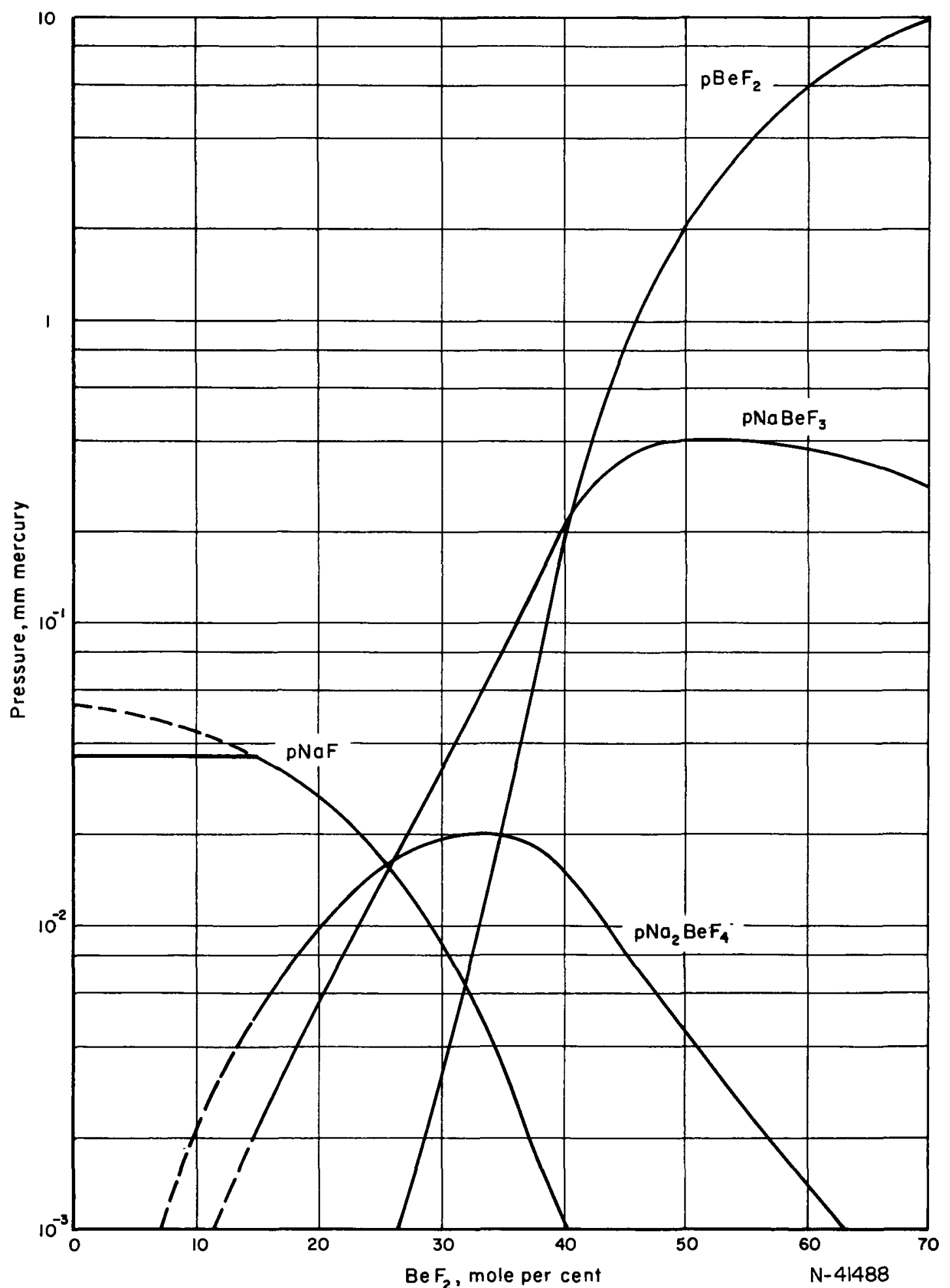

FIGURE 11. PARTIAL PRESSURES AT $890 \mathrm{C}$ ON THE BASIS THAT NaF, BeF 2 , $\mathrm{NaBeF}_{3}, \mathrm{AND} \mathrm{NaBeF}_{4}$ EXIST IN VAPOR PHASE 


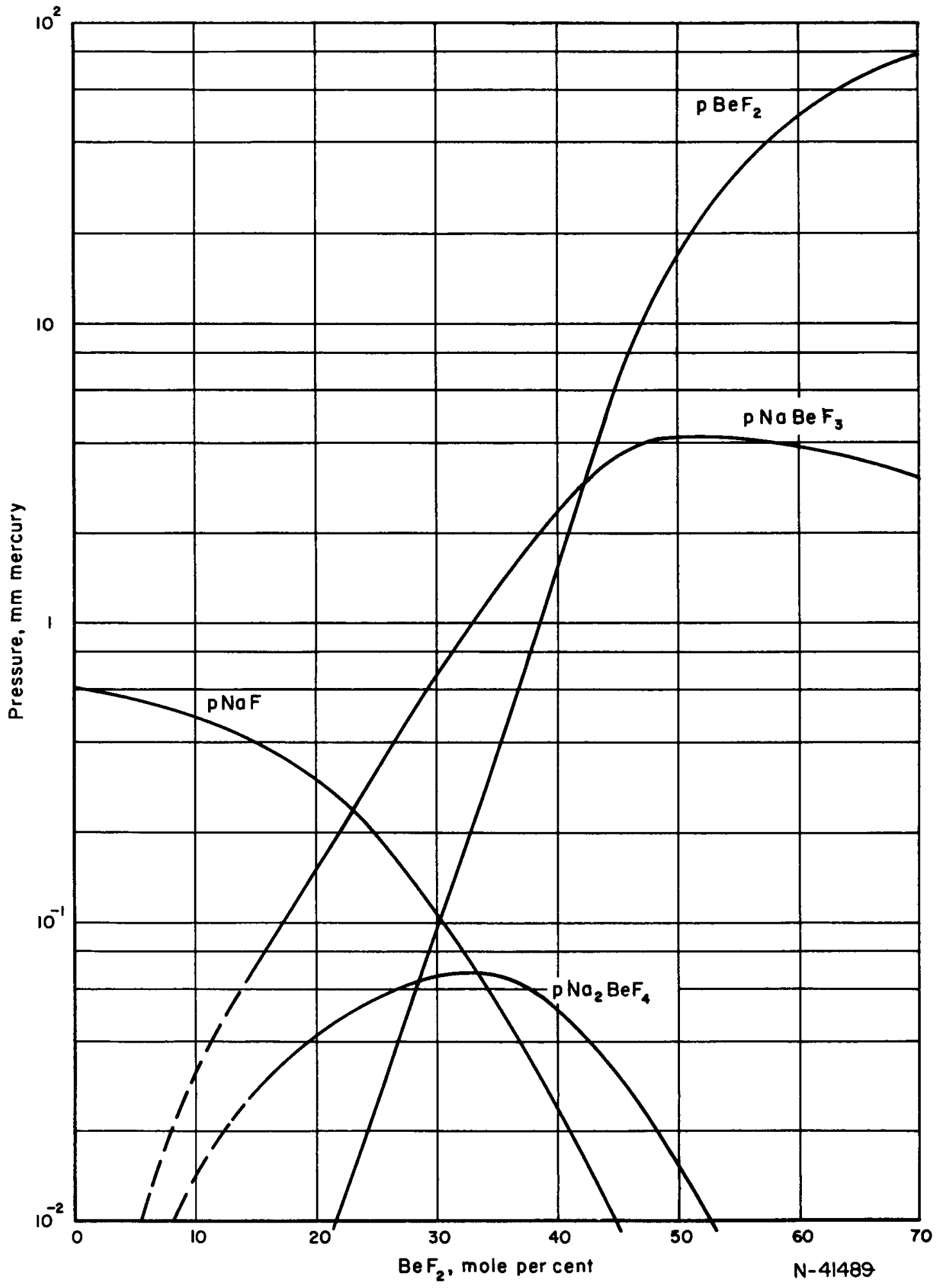

FIGURE 12. PARTIAL PRESSURES AT $1017 \mathrm{C}$ ON THE BASIS THAT NaF, BeF 2 , $\mathrm{NaBeF}_{3}$, AND $\mathrm{Na}_{2} \mathrm{BeF}_{4}$ EXIST IN VAPOR PHASE 
TABLE 4. DERIVED VAPOR-PRESSURE CONSTANTS FOR THE NaF-BeF 2 SYSTEM ON THE BASIS THAT THE VAPOR PHASE IS COMPOSED OF NaF, BeF 2 , $\mathrm{NaBeF}_{3}, \mathrm{AND} \mathrm{Na}_{2} \mathrm{BeF}_{4}$

$$
\log p=A-\frac{B \times 10^{3}}{T(K)}
$$

\begin{tabular}{|c|c|c|c|c|c|c|c|c|}
\hline \multirow{2}{*}{$\begin{array}{l}\text { Composition, } \\
\text { mole per cent } \\
\mathrm{BeF}_{2}\end{array}$} & \multicolumn{2}{|c|}{$\mathrm{pBeF}_{2}$} & \multicolumn{2}{|c|}{ p NaF } & \multicolumn{2}{|c|}{$\mathrm{pNaBeF}_{3}$} & \multicolumn{2}{|c|}{$\mathrm{pNa}_{2} \mathrm{BeF}_{4}$} \\
\hline & $\bar{A}$ & $\bar{B}$ & $\bar{A}$ & $\bar{B}$ & A & $\bar{B}$ & $\overline{\mathrm{A}}$ & B \\
\hline 73.9 & 10.507 & 11.047 & 8.81 & 15.68 & 9.771 & 12.064 & 1.593 & 5.848 \\
\hline 58.8 & 10.024 & 10.810 & 9.36 & 15.78 & 9.843 & 11.938 & 2.286 & 5.918 \\
\hline 50.0 & 9.536 & 10.726 & 10.04 & 16.07 & 9.903 & 11.977 & 3.084 & 6.320 \\
\hline 39.5 & 8.916 & 11.353 & 10.56 & 15.68 & 9.942 & 12.391 & 3.513 & 6.183 \\
\hline 31.5 & 12.35 & 17.01 & 8.93 & 12.89 & 11.702 & 15.208 & 3.651 & 6.221 \\
\hline 24.5 & 12.31 & 18.06 & 9.077 & 12.598 & 11.930 & 16.095 & 3.985 & 6.769 \\
\hline 19.2 & 12.76 & 19.29 & 9.126 & 12.426 & 12.33 & 17.04 & 4.517 & 7.637 \\
\hline 15.0 & 13.18 & 20.32 & 9.212 & 12.391 & 12.82 & 18.01 & 5.04 & 8.51 \\
\hline
\end{tabular}


3

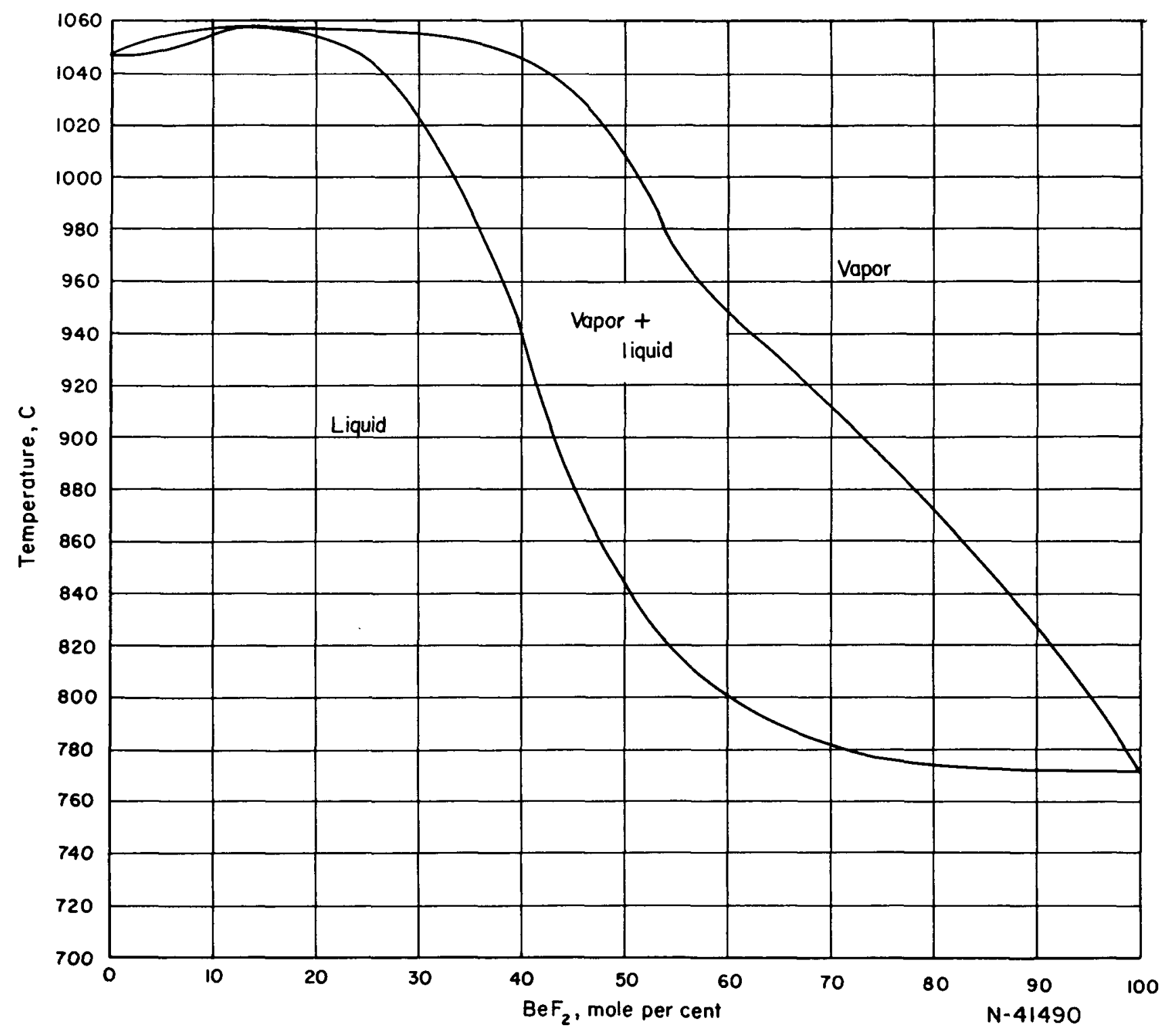

FIGURE 13. PHASE DIAGRAM FOR THE NaF-BeF 2 SYSTEM AT A PRESSURE OF 1 MM MERCURY 


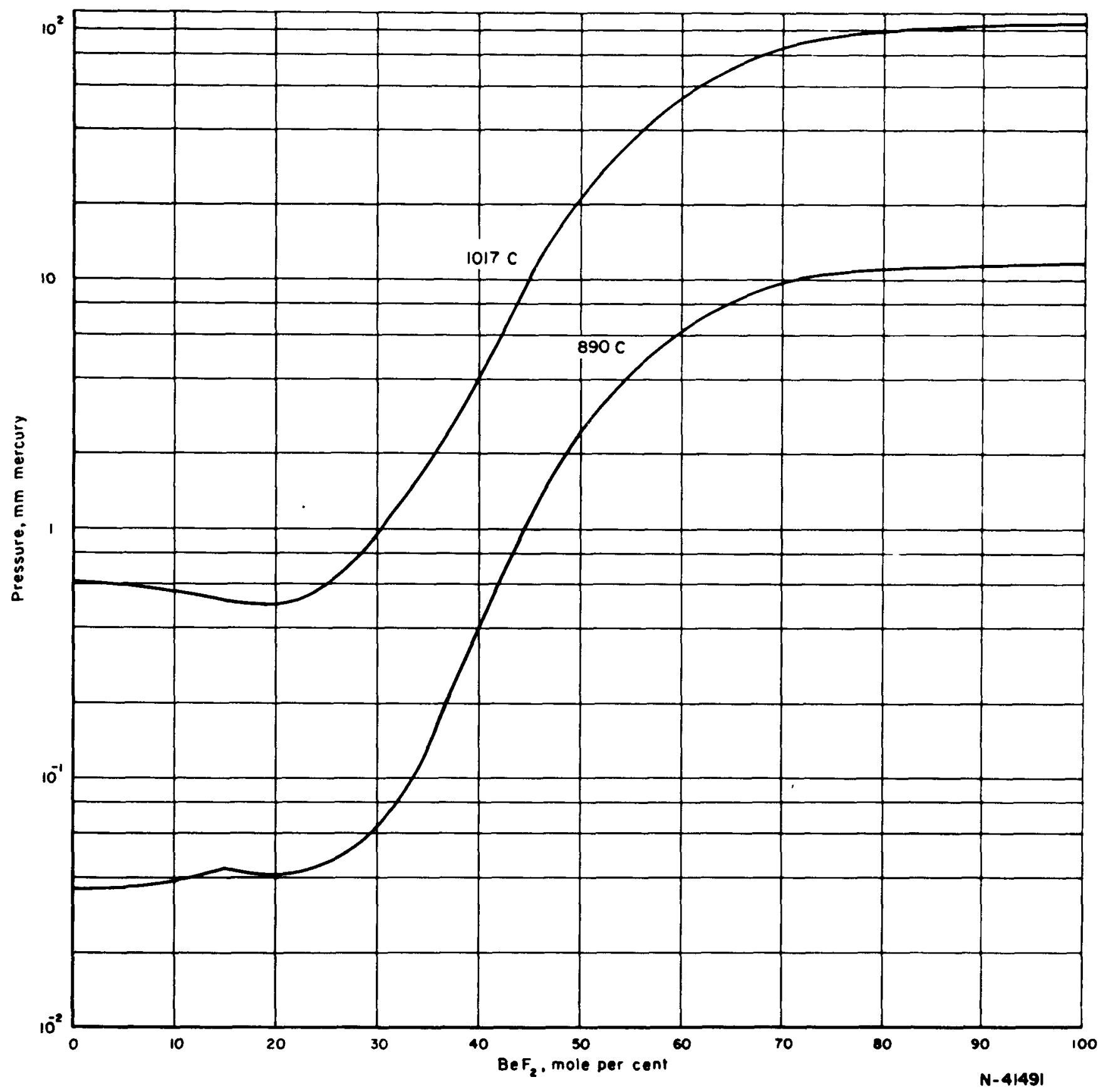

FIGURE 14. TOTAL VAPOR PRESSURE OF NaF-BeF 2 SYSTEM AT $890 \mathrm{C}$ AND $1017 \mathrm{C}$ ON THE BASIS THAT NaF, BeF 2 , AND $\mathrm{Na}_{2} \mathrm{BeF}_{4}$ EXIST IN VAPOR PHASE 


\section{REFERENCES}

(1) Sense, K. A., Bowman, R. E., Stone, R. W., Snyder, M. J., Filbert, Jr., R. B., "Vapor Pressures of the Sodium Fluoride-Zirconium Fluoride System and Derived Information", BMI-1064 (January 9, 1956).

(2) Sense, K. A., Snyder, M. J., and Clegg, J. W., "Vapor Pressures of Beryllium Fluoride and Zirconium Fluoride", BMI-852 (July 13, 1953), Confidential.

(3) Thilo, E., and Schröder, H., Z. physik. chem., 197, 41 (1951).

(4) Miller, R. C., and Kusch, P., J. Chem. Phys., 25, 860-876 (1956).

KAS:RWS:RBF/mmk 